\title{
CPA FIRM'S CLOUD AUDITING PROVIDER FOR PERFORMANCE EVALUATION AND IMPROVEMENT: AN EMPIRICAL CASE OF CHINA
}

\author{
Kuang-Hua $\mathrm{HU}^{1,2}$, Fu-Hsiang CHEN ${ }^{3 *}$, Gwo-Hshiung TZENG ${ }^{4}$ \\ ${ }^{1}$ Accounting School, Nanfang College of Sun Yat-Sen University, China \\ ${ }^{2}$ Finance and Accounting Research Center, Nanfang College of Sun Yat-Sen University, China \\ ${ }^{3}$ Department and Graduate School of Accounting, Chinese Culture University, Taiwan \\ ${ }^{4}$ Graduate Institute of Urban Planning, College of Public Affairs, National Taipei University, Taiwan
}

Received 13 September 2017, accepted 31 July 2018

\begin{abstract}
While CPA (Certified Public Accountant) firms utilize cloud auditing technologies to generate auditing reports and convey information to their clients in the Internet of Things (IoT) Era, they often cannot determine whether cloud auditing is a secure and effective form of communication with clients. Strategies related to cloud auditing provider evaluation and improvement planning are inherently multiple attribute decision making (MADM) issues and are very important to the auditor industry. To overcome these problems, this paper proposes an evaluation and improvement planning model to be a reference for CPA firms selecting the best cloud auditing provider, and illustrates an application of such a model through an empirical case study. The DEMATEL (decisionmaking trial and evaluation laboratory) approach is first used to analyze the interactive influence relationship map (IIRM) between the criteria and dimensions of cloud auditing technology. DANP (DEMATEL-based ANP) is then employed to calculate the influential weights of the dimensions and criteria. Finally, the modified VIKOR method is utilized to provide improvement priorities for performance cloud auditing provider satisfaction. Based on expert interviews, the recommendations for improvement priorities are privacy, security, processing integrity, availability, and confidentiality. This approach is expected to support the auditor industry to systematically improve their cloud auditing provider selection.
\end{abstract}

Keywords: CPA (Certified Public Accountant), Cloud computing, provider selection, MADM (multiple attribute decision making), DEMATEL technique, IIRM (interactive influence relationship map), DANP (DEMATEL-based ANP), modified VIKOR method.

JEL Classification: M15, M41, M42, O14, O33.

*Corresponding author. E-mail: chenfuhsiang1@gmail.com

This is an Open Access article distributed under the terms of the Creative Commons Attribution License (http://creativecommons. $\mathrm{org} / \mathrm{licenses} / \mathrm{by} / 4.0 /$ ), which permits unrestricted use, distribution, and reproduction in any medium, provided the original author and source are credited. 


\section{Introduction}

Cloud auditing is a major transformation for CPA (Certified Public Accountant) firms in information technology (IT) auditing, as it is expected to enhance the scope and competitiveness of the economy, and can start running in a short time. This report concerns the utilization of cloud computing technology and concepts to build the accounting information infrastructure and services in an IoT (Internet of Things) Era. CPA firms may purchase or lease services from cloud auditing providers according to their business scale and development, in order to avoid resource insufficiency or redundancy. The advantages of scalability related to cost, maintenance, management, reliability, and cloud auditing are the reasons for the motivation of CPA firms to apply this method. Studies on cloud auditing are still in the infancy stage, although there are some addressing the selection of corporate cloud suppliers (Repschläger, Wind, Zarnekow, \& Turowski, 2011; Chen, H. K., Lin, \& Chen, J. H., 2014; Kwon \& Seo, 2014; Ghosh, N., Ghosh, S. K., \& Das, 2015; Chahal \& Singh, 2016). As auditing is a highly specialized domain (vs. general operations), the framework for the selection of cloud auditing providers by CPA firms is different from the practices in most companies. An indepth examination of this issue can assist CPA firms to operate in this knowledge-extensive business environment, which relies heavily upon IT (information technology) (Yigitbasioglu, 2015). For instance, many auditors and CPA firms use computer-assisted auditing techniques and support systems (Dowling \& Leech, 2014; Van Akkeren, Buckby, \& MacKenzie, 2013). However, cloud outsourcing of corporate IT services (e.g. IaaS, PaaS, and SaaS) makes it difficult for CPA firms to apply appropriate controls to cloud auditing environments. This is an entirely new challenge for CPA firms.

Cloud computing is similar to outsourcing, meaning companies purchase one or multiple business procedures from cloud auditing providers, thus, it is possible that all the operational processes are dependent on a single IT infrastructure. Therefore, CPA firms must implement their practices in the cloud auditing environment. If CPA firms are planning to use cloud auditing, then it is essential to properly select cloud computing services. While cloud computing services are like network services (Zhu \& Lee, 2016), auditing in the cloud computing environment comes with a greater degree of complexity than traditional IT auditing (Chou, 2015), thus, it is difficult to have a perfect solution. This is a daunting challenge, but a necessary task for CPA firms to select a suitable provider to keep up with the complexity of international development and the growing use of cloud computing.

In its 2011 Service Organization Control Report (SOC Report, AICPA 2013a), the American Institute of Certified Public Accountants (AICPA) proposed that there are three different purposes for professional service providers to address internal controls: SOC1, SOC2, and SOC3. SOC1 produces audit opinions on the internal control of service providers working for audit customers for financial auditing. This should be based on SSAE 16 (Statement on Standards for Attestation Engagements No. 16, SSAE 16) and Reporting on Controls at a Service Organization, i.e. the authoritative guidance for reporting on service organizations (Nicolaou, C. A., Nicolaou, A. I., \& Nicolaou, G. D., 2012). SSAE 16 is the template for CPA firms in the assessment and selection of service providers, where the internal control standards comprise a variety of service and management procedures. SOC 1 , which is formulated 
on the basis of SSAE 16, outlines a series of inspection activities conducted by auditors on the control of service organizations. Such control could be related to the internal control of the relevant user entity's financing report.

AICPA and the Canadian Institute of Chartered Accountants (CICA) subsequently developed a set of trust services criteria in relation to networks and systems, and these principles and standards have been incorporated into the SOC 2 and SOC 3 reports. The SOC 2 report deals with the processing and control details regarding the installation by cloud computing service providers. Auditors are required to inform clients of their findings during the auditing process, thus, it has high demand to meet the requests of clients for auditing guarantee in an extremely complex cloud computing environment. This is why the guidelines for the SOC 2 standards, as based on the Trusted Services framework, come into play. Auditors adhere to the SOC 2 protocol, while the computing service providers give a warranty for all SaaS, PaaS, and IaaS services. For instance, Salesforce (a cloud computing service provider) conducts a trust service survey as part of its SaaS offerings, and then, the accountants give their comments on the claims regarding system security, usability, and confidentiality. Accountants and auditors of financial reports play a pivotal role in ensuring the control and risk management policies adopted by the cloud computing service providers, which helps providers to assist in the deployment of cloud computing by CPA firms and addresses their concerns about information security. The SOC 3 standards provide a framework for audit reports regarding whether the systems are in compliance with Trust Services criteria, and whether the control measures are effective during the audit period.

The factors (features) and sub-factors that CPA firms deal with concerning the services provided by suppliers are often not independent; rather, they may affect each other in the context of cloud auditing. Multiple attribute decision making (MADM) technology can address the issues regarding the interworking of factors and sub-factors. MADM is one type of MCDM technique, which can simultaneously consider multiple attributes, in order to help decision-makers to evaluate each proposal, set priorities according to specific characteristics, and select the best solutions. As cloud auditing in the real world presents a dynamic problem, MADM is the best tool to resolve this issue.

The assessment reports of SOC 1, 2, and 3 (Nicolaou et al., 2012), as well as the results of experts' interviews, confirm the list of multiple dimensions and sub-factors regarding how CPA firms select and evaluate cloud auditing providers. As these dimensions and subfactors are often interrelated, this paper adopts the hybrid MADM method, which combines Decision Making Trial and Evaluation Laboratory (DEMATEL), DEMATEL-Based Analytic Network Process (DANP), and modified VlseKriterijumska Optimizacija I Kompromisno Resenje (modified VIKOR), as based on the interactive influence relationship map (IIRM), in order to overcome this issue.

The hybrid MADM model can resolve the real-world problem of how CPA firms select cloud auditing providers. This research compared to past studies fills the gap in the following five ways. First, IIRM identifies how and in which direction the criteria of selecting cloud auditing provider can impact themselves and one another, which can assist CPA firms management decision makers in realizing the root issues of performance evaluation and devising 
cloud auditing providers improvement strategies. Second, this study utilizes the interrelationship model derived with DANP deals with the dependence and feedback relationships of the selection criteria for CPA firms to choose the best cloud auditing providers. Third, this research adopt the modified VIKOR approach provides a list of the individual and overall factors for evaluating and improving the performance gap of each criterion and dimension, in order to facilitate the best strategies of development for implementing the performance gap improvement toward closing zero, i.e., attaining the aspiration levels by systematics based on IIRM; this can avoid the loophole of selecting the seemingly best solution from inferior choices/options/alternatives (i.e. "stop-gap piecemeal"); the modified VIKOR evaluation can be used for ranking and selection, as well as for identifying the performance gap improvement for cloud auditing providers. Fourth, Decisions are made simultaneously according to the interactive influence relationship of indicators, as obtained by the DEMATEL technique, and the performance of each indicator measured by modified VIKOR. Namely, priority is given to improving those with larger performance gaps; at the same time the interactive influence relationship between the indicators should be considered (see Figure 4), which can achieve the synergy effect in improvement strategies. Fifth, emphasis in the field has shifted from ranking when determining the most preferable approaches to improvement of existing methods by systematics and the prioritization of the influencing factors can serve as a reference to CPA firms in the selection of cloud auditing providers. At the same time, the hybrid MADM is a step forward from a list of simplistic rankings and the selection of optimal alternatives for performance improvements and measures.

The remainder of this article is organized, as follows. Section 1 reviews the existing literature on cloud service metrics for CPA firms. Section 2 conducts a brief review of cloud service ranking/selection approaches. Section 3 proposes our research design and methodology. Section 4 reports our empirical results, while last section offers the conclusion.

\section{Cloud service metrics for CPA firms}

The cloud auditing service providers mentioned in this paper refer to the cloud computing service providers that can construct cloud auditing services for CPA firms (such as Amazon, Google, IBM, Salesforce.com, etc.). Due to the characteristics and technology of cloud computing, could service providers can elastically design a customized cloud auditing model according to the requirements of the CPA firms. The empirical results in this paper can be used as a reference basis for CPA firms and cloud service providers to negotiate design demands, and thus, tailor its optimal auditing procedures (system) on the basis of the cloud computing. For instance, cloud auditing service providers - Amazon companies promoted two cloud computing services in 2016: S3 (Simple Storage Service) and EC2 (Elastic Compute Cloud), which are widely praised. Among them, Amazon S3 can provide complete safety and compliance functions, and even meet the strictest regulatory requirements. It provides clients with high-elasticity demands, as well as the ability to manage their data according to cost optimization, access control, and compliance. Therefore, Amazon S3 can provide customized functions and an auditing service platform with stable implementation efficiency, and set up an auditing knowledge base, where CPA firms can share their auditing knowledge base and 
computing system, and audit working papers of various industry categories, expert conditions, and the matters to be noticed and checked, in order to inherit or preserve the industrial knowledge valued by the CPA firm and provide them to new auditors to understand the working contents in a short time. For instance, company A (cloud auditing service providers) has designed and evaluated the effectiveness of their system controls over the cloud computing environment to achieve the services' commitments and system requirements, as based on the AICPA's TSP section 100A, Trust Services Principles and Criteria for Security, Availability, Processing Integrity, Confidentiality, and Privacy.

Before the launch of cloud computing, the AICPA (American Institute of Certified Public Accountants) defined the prerequisites for service organizations and providers that offer outsourcing audit services or operational procedures. These requirements include the Statement on Auditing Standards No. 70 (SAS 70), i.e. the audit standards for the effectiveness of the service organization on internal control. With the continuous development of cloud computing, the AICPA revised SAS 70 in 2011, and published guidance indicators for SSAE 16 auditors. The SOC 1 report was released in an attempt to keep up with globally recognized accounting standards (such as ISAE 3402 in the ISO reporting standard). This report focuses on the internal control of auditing service organizations concerning the financial reporting of user entities. SOC 2 and SOC 3 place emphasis on the opinion reporting of the confirmatory services of information systems in the IoT Era. Examples are confirmatory or assurance opinions regarding the safeguarding of data centers on the cloud. A wider set of service principles and criteria serves as a benchmark for building cloud providers on a platform that is consistent with the practices of auditing.

In sum, the AICPA's SOC reports are the most widely accepted and adopted set of criteria for CPA firms to assess the internal control of cloud auditing providers. Therefore, this paper refers to the SOC reports (SOC 1,2, and 3), as defined in the cloud audit service provider for CPA firms, to evaluate and conceptualize the framework. A literature review is conducted on the characteristics of Chinese CPA firms. The findings are combined with brainstorming by experts and scholars, as well as in-depth interviews with senior executives in the IT division of CPA firms, in order to develop five dimensions: security, availability, processing integrity, confidentiality, and privacy (Figure 1). These five dimensions can be used as reference for the selection by CPA firms for the providers of cloud auditing services. Each dimension is detailed, as follows.

\subsection{Security}

One of the biggest advantages of cloud auditing is to allow auditors to carry out work at any time, from anywhere, and on any device; however, this leads to an unexpected risks regarding security and privacy (Liu, Wang, \& Wu, 2012; Ramachandran \& Chang, 2016). In the cloud computing environment, the impact of any damage on software and hardware resources is even more significant than on users of the Internet in the IoT Era. Security is a key factor for the reliability of audit services (Shin, 2013). However, the storage and processing of clients' data and the auditing procedures by CPA firms mean that improper handling of security, confidentiality, and ownership will cause destructive consequences. 


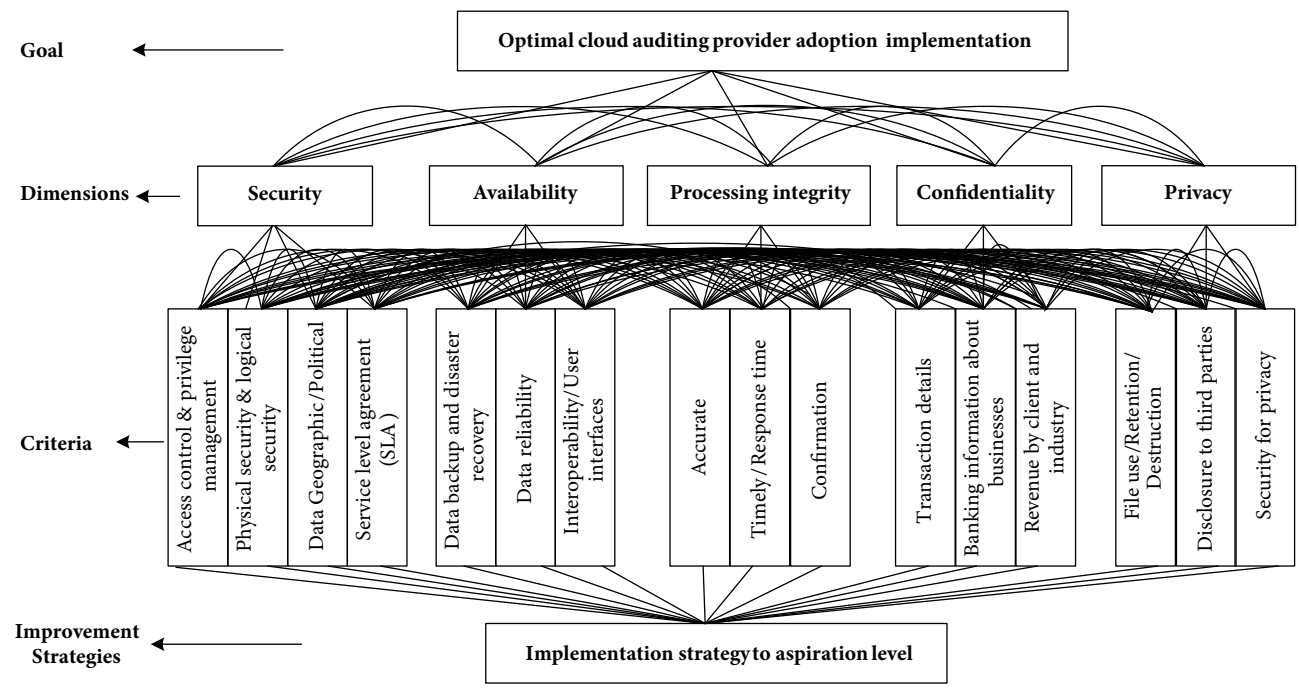

Figure 1. Analytic framework of cloud auditing provider adoption influence network

Therefore, the security of the cloud computing environment is the primary consideration for adopting cloud auditing by CPA firms. Yigitbasioglu (2015) conducted a survey on auditors and IT professionals of CPA firms in Australia, and all the respondents agreed that the confidentiality of data and security risks were the major obstacles for CPA firms to migrate data to the cloud. If data are spread over different countries and jurisdictions, this is a special case, as it causes legal and governance issues. It is essential for cloud auditing service providers to offer data security protection features, such as authorization, access control, encryption technologies, and security management. The deployment of cloud computing procedures by auditing service providers should be supported with cutting-edge technology to ensure the management of the privileges of authorization and access, in order to enhance system security (Mackay, Baker, \& Al-Yasiri, 2012). When cloud audits are created and run, the data of CPA firms' customers are stored on servers, thus, the day-to-day operation and maintenance of servers are the responsibility of suppliers, as based on service level agreements (SLAs) (Buyya, Yeo, Venugopal, Broberg, \& Brandic, 2009; Zhang, Ye, Shi, Du, \& Guizani, 2014; Wang, Wood, Abdul-Rahman, \& Lee, 2016). In other words, SLAs are an important assurance for the works of CPA firms.

\subsection{Availability}

As the services rendered by cloud computing are over networks, it is important to ensure data availability, reliability, and integrity (Sood, 2012), in order to maintain the continuity and quality of audits carried out by CPA firms. In fact, once CPA firms and their clients decide to put data in the cloud as part of outsourcing to cloud audit service providers, they no longer own the data. Cloud computing puts firms at even greater risks (compared to other companies) if data are lost or damaged. To avoid security risks and assist CPA firms in the 
construction of cloud auditing platforms, it is critical for providers to ensure the integrity and usability of outsourced data, as well as data forensics and credibility on the cloud (Yavuz \& Ning, 2009; Zhu, Hu, Ahn, \& Yau, 2012). Put differently, the auditing works carried out by CPA firms in a cloud computing environment requires even more robust system reliability and data security; however, the nature of cloud computing is such that providers are unable to provide $100 \%$ security assurance. For instance, Amazon offers $99.9 \%$ guarantee for its service levels for S3 data storage. Another case in point is the $99.5 \%$ guarantee for EC2's servers (Nicolaou et al., 2012). This implies the possibility of data loss, damage, or transmission disruption; however, data backup and disaster recovery (Krishna, Kiran, Murali, \& Reddy, 2016) can provide a remedy ( $\mathrm{Du} \& \mathrm{Li}, 2011$; Mansouri, 2016).

The other issue is when IT services used by CPA firms and audit clients come from different vendors, meaning there is incompatibility between different systems and products. The interoperability between user interface standardizations and APIs (application programming interfaces) over different clouds presents a major hurdle for the introduction and functioning of cloud audit platforms (Lee, Park, \& Yang, 2015; Mazalov, Lukyanenko, \& Luukkainen, 2015). CCIF (Cloud Computing Interoperability Forum), as initiated by ITU-T (International Telecommunication Union's Telecommunication Standardization Sector), aims to create a unified cloud interface (UCI) and develops an open and standardized cloud interface for the integration of APIs (Lee, Park, \& Yang, 2013). The interoperability of cloud computing will improve the audit efficiency of platforms due to scalability, universality, continuity, and specialty of resources.

\subsection{Processing integrity}

According to the SOC 2 report, processing integrity refers to the complete, accurate, timely, and authorization for system processing (Shkurti \& Muça, 2014). To prevent malicious attacks and ensure a safe cloud computing environment, vendors must safeguard the processing integrity of data (AICPA, 2013b; Zhu \& Lee, 2016). Ren, Yu, Gao, and Xiong (2011) indicated that cloud auditing providers should guarantee the privacy and integrity of outsourced files during the uploading and downloading process. In addition to security and usability, CPA firms must also consider the response time for cloud computing services. As auditors may have to access data anytime and anywhere (Tarmidi, Rasid, Alrazi, \& Roni, 2014; Yigitbasioglu, 2015), it is essential for providers to render necessary services in the shortest time possible once they have received submitted requests. It is also crucial to agree on the average latency time and loss of data packets in a specific period of time. In the audit process, to validate the authenticity of data owned by clients, CPA firms must request electronic confirmation from third parties, such as deposit/loan data from banks, information disclosures to the China Securities Regulatory Commission, and tax filings to tax authorities. In order to improve audit quality and mitigate audit risks, confirmation is a key component of the integrity of IT auditing (Janvrin, Caster, \& Elder, 2010; Bergh, Hinna, Leka, \& Zwetsloot, 2016; Axelsen, Green, \& Ridley, 2017). 


\subsection{Confidentiality}

The storage of data on the cloud means the loss of control over data. It is not impossible for vendors to divulge confidential information to competitors (e.g. transaction details) or hide data leakages to protect their own reputations (Dong et al., 2015). As auditing often involves the business secrets and core tasks of clients, there is a large number of contact points for internal information associated with human resources, financial capability, materials availability, and audit assessments. The use of cloud auditing by CPA firms involves auditing confidentiality risks; any negligence may lead to the leak of massive amounts of data, resulting in tremendous loss to the companies and inestimable consequences. Data confidentiality is a challenging task, and vendors should provide a robust and powerful mechanism to maintain the information confidentiality of corporations (i.e. audit clients) and CPA firms (Liu, J., Huang, \& Liu, J. K., 2015). Data confidentiality is one of the key factors to the quality of cloud audit services provided by suppliers (Dong et al., 2015). However, neither the AICPA nor the CICA (Canadian Institute of Chartered Accountants) have clearly defined access to Generally Accepted Privacy Principles (GAPP) regarding confidential information. In most cases, the regulations governing confidential information are driven by contractual arrangements.

\subsection{Privacy}

The security and privacy risks associated with the storage of data on the servers of remote suppliers in the cloud computing environment are an issue of concern for auditors (Chou, 2015). The SOC reports posit that GAPP should serve as the underlying guideline for the appropriate protection and management of personal information. To enable CPAs to provide comprehensive and private services to audit clients, AICPA and CICA released "Privacy Examination and Audit Reports" in GAPP in August 2009 (AICPA/CICA, 2009). These privacy principles are based on internationally accepted fairness information, and encompass many privacy laws and regulations around the world, and hence, are considered the best practice in privacy protection (Prosch, 2008). Cloud providers set up restrictions regarding the use of personal information for specific purposes, thus, personal information retained ex-post must be properly handled, meaning after the completion of tasks or according to legal requirements, in order to ensure information privacy (Toy \& Hay, 2015). GAPP dictates that providers shall convey to third parties the privacy policies, specific conditions, or requests for personal information processing before sharing personal information. It is also necessary to obtain written agreements from third parties indicating their compliance with the relevant policies or requests for the privacy practices of personal information disclosed by suppliers. In general, CPAs should ensure privacy throughout the entire auditing process, from transfers and analysis to the processing of physical and electronic evidence (Gray, 2008).

\section{A brief review of cloud service ranking/selection approaches}

There is a lack of studies on the selection of cloud auditing providers. In fact, the selection criteria for cloud auditing suppliers share similar network relations with the choice of cloud computing suppliers. Therefore, the techniques used to select cloud computing providers can serve as a template for this paper. 
Literature shows that the selection for cloud computing providers are MCDM (multicriteria decision making) technologies (Limam \& Boutaba, 2010; Martens, Teuteberg, \& Gräuler, 2011; Nie, She, \& Chen, 2012), optimization methods (Wang, Zhang, \& Liu, 2009; Yang, Lin, \& Dou, 2013; Zheng, Wu, Zhang, Lyu, \& Wang, 2013; Martens \& Teuteberg, 2012), and logic approaches (Dastjerdi, Tabatabaei, \& Buyya, 2010; Chen, Yan, Zhao, Lee, \& Singhal, 2012; Kanagasabai, 2012). Among these methods, MCDM is the most frequently used. In addition, AHP/ANP (analytic hierarchy process/analytic network process) (Godse \& Mulik, 2009; Menzel, Schönherr, \& Tai, 2013), MAUT (Limam \& Boutaba, 2010; Cavalcante et al., 2012), and SAW (simple additive weighting) (Afshari, Mojahed, \& Yusuff, 2010; Zhao, Ren, $\mathrm{Li}$, \& Sakurai, 2012) are all very popular. The following is a high-level explanation of all MCDM techniques.

Kleijnen (2005) contends that MCDM is a method that can simultaneously consider multiple attributes decision making (MADM), and help decision-makers to assess and prioritize a finite number of proposals according to the characteristics and attributes, in order to choose the best solutions. AHP (Saaty, 1990), which assumes that the criteria are independent, is a widely used method to evaluate and select services. Pair-wise comparisons of factors in the same hierarchical level are performed to gauge the relative importance of the factors, and assumes that the criteria are independent. This approach can deal with complex issues in a systematic manner, in order to determine priorities and select the best options accordingly, under the assumptions. The AHP method reduces the probability of erroneous decisions with only its hierarchical structure and quantitative techniques. ANP (Saaty, 2004) is an extension of AHP, which considers the interrelations of factors to solve dependence and feedback problems between factors (also denoted as clusters) and criteria (inner factors/clusters) in diagonal matrices also under independent assumption (i.e., zero matrix, $Z_{i i}=\mathbf{0}$ ) or exhibit self-relation (identity matrix, $\boldsymbol{I}$ ), and feeds these interrelationships back to the overall structure to form a relational network. This approach is more able to reflect the decision-making process in the real world.

MAUT (Multi-Attribute Utility Theory) is an application of the expected utility theory (Sanayei, Mousavi, Abdi, \& Mohaghar, 2008). It expresses the subjective preferences of decision makers from the perspective of multiple attributes, and constructs a utility function with mathematical programming, which is conducted by simplifying the complex issues in the multi-attribute utility function into a utility function of a single attribute or linear multiattributes. Afterwards, the functions of individual components are combined into one aggregate utility function to facilitate the ranking and selection of known alternatives (Ko \& Fujita, 2016). The MAUT method, was which developed to consider multiple goals, has a robust theoretic basis and has been used for decision making in different domains. However, its qualitative criteria and assessments are even more complex than AHP, and thus, is less used in academic studies due to its unrealistic assumptions in Statistics and Economics in the real world situations.

The SAW method (Zionts \& Wallenius, 1983; Afshari et al., 2010) is a simple and most frequently used multi-attribute decision-making method, and because its concept is based on weighted average, it is also called the weighted linear combination or scoring method. This method calculates the weighted average of every alternative, produces the rankings, and 
identifies the best solutions based on these numbers. However, as the presumption is that each attribute is independent, accurate measurements will not be possible if some alternatives have qualitative or uncertain structure.

According to the previous descriptions, in practice for solving actual real-world problems, we must relax some unrealistic assumptions in Statistics and Economics for satisfying realworld situations. Therefore, this study uses the DEMATEL technique to identify the interrelationships among the sixteen factors of IIRM (interactive influence relationship map), and seeks to obtain more precise IWs (influential weights) that fit real-world problems. Therefore, the IWs of DANP are in line with practical needs; some unreasonable assumptions in the AHP and ANP are relaxed. Saaty (1996) proposed ANP to solve dependence and feedback problems between factors (also denoted as clusters) and criteria (inner factors/clusters) in diagonal matrices under the assumption that they are independent (zero matrix, $\boldsymbol{Z}_{i i}=\mathbf{0}$ ) or exhibit self-relation (Identity matrix, $\boldsymbol{I}$ ). The weighted super-matrix is obtained using equal weights. Saatys' ANP eliminates the limitations of the Analytic Hierarchy Process (AHP), which assumes that all criteria (inner and outer dimensions/clusters) are independent. The difference between these methods is that ANP is applied to decision-making problems for interrelationships in outer factors; while AHP assumes the independence of outer and inner factors (i.e., all factors and criteria). Consequently, if an influential interrelationship exists between factors and criteria, and is not considered, the outcome of the decision-makers may be affected. Therefore, this study uses a hybrid MADM model developed for improving CPA firm's cloud auditing provider performance. This study adopts the DEMATEL technique through expert knowledge in practical experience to establish an influence relationship matrix for constructing an interactive influence relationship map (IIRM) and determining the IWs (influential weights) of the DANP, which is based on the ANP concept (Saaty 1996) to solve practical problems (Chen \& Tzeng, 2015; Hu, Chen, Tzeng, \& Lee, 2015; Deng, Wen, Chen, \& Lin, 2018). Hence, the calculation of the IWs of DANP involves the following steps: Step 1: establishing total influence relation matrix $\boldsymbol{T}_{C}$; Step 2: normalize the total influence relation matrix $\boldsymbol{T}_{C}$ as $\boldsymbol{T}_{C}^{\beta}$ by criteria and by $\boldsymbol{T}_{C}$ as $\boldsymbol{T}_{C}^{\beta}$ factors (dimensions); Step 3: determine un-weighted super-matrix $W=\left(T_{C}^{\beta}\right)^{\prime}$; Step 4: obtain weighted super-matrix $W^{\beta}=T_{D}^{\beta} \boldsymbol{W}$; Step 4: calculate the limit of super-matrix $\boldsymbol{W}^{\beta}$, in order to obtain influential weights $\boldsymbol{w}=\left(w_{1}, \ldots, w_{j}, \ldots, w_{n}\right)$.

\section{Research design and method}

In summary, to date, there is no perfect methodology. DEMATEL is adapted for provider evaluation and performance improvement, such as Tzeng's research group (Liou, Chuang, \& Tzeng, 2014). The purpose of this paper is to understand how cloud auditing factors or subfactors are either interrelated or independent, and develop cloud auditing provider performance evaluations and improvement models for CPA firms. Decision makers must consider the mutual effects between factors (or called dimensions) and sub-factors (or called criteria), in order to identify the key influential factors (criteria) and determine remedial measures to improve audit quality and efficiency in the cloud computing infrastructure. When 
decision-makers face a variety of options, it is difficult to choose, thus, the best approach is to identify the key factors (dimensions and criteria) that are most influential to other factors. These factors will then be prioritized in the selection of cloud auditing providers. The hybrid MADM model, as proposed by this paper, can resolve this dynamic complex issue. First, this paper applies the DEMATEL technique to establish an interactive influence relationship map (IIRM) through an influence relation matrix in the analysis of the interrelated factors considered by CPA firms in the selection of cloud auditing providers. Second, on the basic concept of ANP (Saaty, 1996), this paper combines the DEMATEL technique with the influence weights, as calculated by ANP criteria, to derive the influence weights of DANP (DEMATEL-based ANP). These weights are used in the modified VIKOR method as performance weightings. Finally, the modified VIKOR method is used to measure the performance value of each criterion, in order to identify the gaps of criteria, and how improve such gaps toward closing zero, in order to achieve the aspiration level required to meet the demands and needs of CPA firms to select the best cloud auditing providers. This section comprises four subsections: first, develop an IIRM (interactive influence relationship map) using the DEMATEL technique; second, calculate the influential weights of DANP, as based on DEMATEL; third, evaluate the total performance gap by the modified VIKOR method; and finally, formulate the questionnaires and results. The relatively traditional MADM approach is only used for ranking and selection, and cannot be used for improvement, thus, this research adopts a hybrid MADM model for solving real-world problems. This study intends to provide distinction from the traditional 'MADM approach'. This point is that, one of our new concepts of "relatively good solutions from existing alternatives" uses Max-Min for deriving the positive-ideal solution and negative-ideal solution, which are replaced by aspiration levels and the worst value in the traditional approach to pursue continuous improvements (through innovation/creativity, combining DANP), as based on IIRM for achieving/closing the aspiration level (whole systems, called "a new hybrid modified MADM model"). The hybrid MADM processes are illustrated in Figure 2.

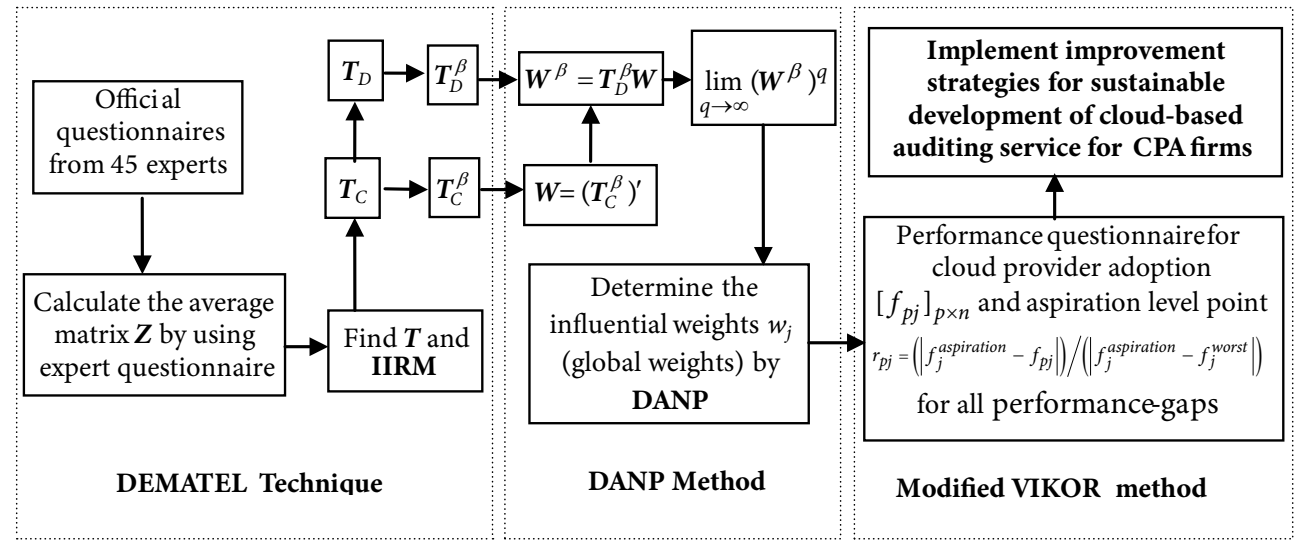

Figure 2. A mixed-model procedure of new HMMADM for cloud auditing provider adoption 


\subsection{Using the DEMATEL technique to build IIRM}

The DEMATEL technique, which is called an interactive influence relationship map (IIRM), has been widely used to resolve complex network relation problems, and can address the relationships among the criteria. The DEMATEL technique involves four steps. The first step is to construct a system with $\mathrm{n}$ elements/indicators (or call criteria) and use pairwise comparisons to develop an assessment scale. A five-point scale ranging from 0 (absolutely no influence) to 4 (very high influence) is used as natural language for pairwise comparison according to the perception/opinion of experts. The second step calculates the influence matrix from preliminary matrix $\mathrm{X}$. The third step normalizes matrix $\mathrm{Z}$ for obtaining relation matrix $\mathrm{D}$, where the sum of at least one column or row equals one, but not all. Finally, the fourth step exports the total influence relation matrix $\mathrm{T}$ and maps out the interactive influence relationship map (IIRM). Details of the DEMATEL technique are illustrated in Appendix A.

\subsection{Determining the influential weights of DANP}

DANP (DEMATEL-based ANP) is applied to solve non-linear and complex relations, and to obtain the relatively influential weights of criteria. DANP has been applied to solve practical decision-making problems, such as Websites Quality (Chen, Tzeng, \& Chang, 2015), performance evaluation/improvement (Hsu, Tsai, \& Tzeng, 2017; Hu, Wei, \& Tzeng, 2017; Deng et al., 2018; Liu, Lin, Hsieh, \& Tzeng, 2018), supplier selection (Liou et al., 2014), and internal control (Chen, 2015). The DANP approach is based on the influence relation matrix $\boldsymbol{T}\left(\boldsymbol{T}_{C}=\left[\boldsymbol{t}_{i j}\right]_{n \times n}\right.$ by criteria and $\boldsymbol{T}_{D}=\left[\boldsymbol{t}_{i j}\right]_{m \times m}$ by dimensions) of the DEMATEL technique and the basic concept of ANP, and the unweighted super-matrix $W=\left(T_{C}^{\beta}\right)^{\prime} \quad\left(T_{C}^{\beta}\right.$ shows the normalized influence relation matrix by criteria) and weighted super-matrix $\boldsymbol{W}^{\beta}=\boldsymbol{T}_{D}^{\beta} \boldsymbol{W}$ ( $T_{D}^{\beta}$ shows the normalized influence relation matrix by factors) can be produced. The global vectors of the influence weights of DANP can then be found by $\lim _{q \rightarrow \infty}\left(\boldsymbol{W}^{\beta}\right)^{q}$, where $q$ represents a sufficiently large power. Therefore, these methods solve the problems of dependence and feedback among criteria (Chen, 2015; Shen \& Tzeng, 2016). For further explanation on the DANP procedures, please refer to Appendix B.

\subsection{Modified VIKOR method for measuring performance}

The traditional VIKOR method was introduced by Opricovic (Opricovic, 1998), and proposed by Opricovic and Tzeng (Opricovic \& Tzeng, 2007); its basic concept of a compromise solution (Yu, 1973) could be implemented to resolve the problem of the criterion conflict in the MADM model. Thus, the best alternative in the MADM framework can be selected when managing a multiple-criteria decision-making problem. In this study, the most suitable alternatives (or called criteria) are extracted by the modified VIKOR method, which uses "Aspiration-Worst" as a benchmark to replace the traditional VIKOR approach (at least two or more alternatives, $k \geq 2$ ) of using "Max-Min" as the benchmark. Consequently, the modified VIKOR can be used for ranking and selection among alternatives, can be used for performance gap improvements toward closing zero for reaching aspiration levels, and can even be used for only one (single) alternative issue, as detailed in Appendix C. 


\subsection{Questionnaire development and data collection procedures}

The three-stage design for this study includes five dimensions and criteria, a pre-test questionnaire, and an official questionnaire. The first stage confirms the five dimensions and 28 criteria (see Table 1), as based on SOC of AICPA, GAPP for "CPA, and CA Practitioner Version" by AICPA/CICA (AICPA and CIA, 2009), and related literature. AICPA proposed SOCs are widely accepted for CPAs to examine controls, and can obtain control effectiveness for operations and compliance in the auditing process in a cloud environment. The second stage constitutes the preliminary questionnaire, as based on Table 1 . The pre-test questionnaire for this study is administered to 12 senior CPAs and 12 senior IT experts with in-depth insights to cloud computing from CPA firms in Shanghai, Beijing, Guangzhou, and Shenzhen. The triangular fuzzy numbers are compiled to determine the importance scales with a mean value of 6 and above; the pre-test questionnaire ranges from 0 to 10 points, and a high score indicates higher importance (more than 6 to 10 points in the 16 criteria). This is consistent with the limited number of factors within a single structure according to the recommendation by Saaty (1996) to ensure the consistency and validity of pairwise comparisons. The relative importance of the criteria can be obtained from a questionnaire survey of domain experts, with 16 criteria left over from the 28 criteria. The pre-test results are shown in Table 2.

In the third stage, the official questionnaire and results are formulated according to Table 2. In this stage of this study, the domain experts consist of 25 senior supervisors and 20 IT experts from first-tier cities (such as Shanghai, Beijing, Guangzhou, and Shenzhen), who are quite familiar with cloud auditing and the experts participating in the cloud auditing design and demand, and will use cloud auditing in the future. Each face-to-face interview took 60 to 90 minutes subject to a completed questionnaire from September 2016 to January 2017. The expert questionnaire, the opinions/thoughts of the assessment criteria, and the scales, with anchors ranging from "no influence ( 0 point)" to "very strong influence (4 point)," is $0 \sim 4$ points, respectively, and denote the impact direction of each criterion on another criterion. The results of the questionnaire survey are based on the empirical analysis of the research methods described in this study.

Table 1. The preliminary assessment framework of cloud auditing provider adoption

\begin{tabular}{|c|c|c|c|c|}
\hline \multicolumn{5}{|c|}{ Dimensions } \\
\hline Security & Availability & $\begin{array}{l}\text { Processing } \\
\text { integrity }\end{array}$ & Confidentiality & Privacy \\
\hline $\begin{array}{l}\text { Access control \& } \\
\text { privilege management } \\
\text { Physical security \& } \\
\text { logical security } \\
\text { Security management } \\
\text { Data Geographic/ } \\
\text { Political } \\
\text { Service level } \\
\text { agreement (SLA) }\end{array}$ & \begin{tabular}{|l|} 
Data backup and \\
disaster recovery \\
Data reliability \\
Data \\
maintainability \\
Service resilience \\
Interoperability/ \\
User interfaces \\
Vendor lock-in
\end{tabular} & \begin{tabular}{|l|} 
Complete \\
Accurate \\
Authorize \\
Timely/Response \\
time \\
Confirmation
\end{tabular} & $\begin{array}{l}\text { Transaction } \\
\text { details } \\
\text { Business plans } \\
\text { Banking } \\
\text { information } \\
\text { about businesses } \\
\text { Inventory } \\
\text { availability } \\
\text { Legal documents } \\
\text { Revenue by } \\
\text { client and } \\
\text { industry }\end{array}$ & $\begin{array}{l}\text { File use/Retention/ } \\
\text { Destruction } \\
\text { Disclosure to third } \\
\text { parties } \\
\text { Employee training } \\
\text { Monitoring and } \\
\text { enforcement } \\
\text { Security for privacy } \\
\text { Privacy polices } \\
\text { (Responsibility and } \\
\text { accountability for } \\
\text { policies) }\end{array}$ \\
\hline
\end{tabular}


Table 2. Cloud auditing provider adoption framework for CPA firms

\begin{tabular}{|c|c|c|}
\hline Dimensions/Criteria & Statements of criteria & Sources \\
\hline \multicolumn{3}{|c|}{ Security $(A)$} \\
\hline $\begin{array}{l}\text { Access control } \\
\text { \& privilege } \\
\text { management }\left(a_{1}\right)\end{array}$ & $\begin{array}{l}\text { Cloud auditing providers assure that only } \\
\text { authorized personnel can access or modify the } \\
\text { data. }\end{array}$ & Mackay et al. (2012) \\
\hline $\begin{array}{l}\text { Physical security \& } \\
\text { logical security }\left(a_{2}\right)\end{array}$ & $\begin{array}{l}\text { Cloud auditing providers meet the demand from } \\
\text { private companies (audit clients) or CPA firms } \\
\text { for the protection of physical security and data } \\
\text { security. }\end{array}$ & Shin (2013) \\
\hline $\begin{array}{l}\text { Data Geographic/ } \\
\text { Political }\left(a_{3}\right)\end{array}$ & $\begin{array}{l}\text { The server locations of cloud audit suppliers } \\
\text { for the data of CPA firms or audited companies } \\
\text { (companies), i.e. the service locations, may incur } \\
\text { jurisdiction issues or political risks if the service } \\
\text { locations are overseas. }\end{array}$ & Yigitbasioglu (2015) \\
\hline $\begin{array}{l}\text { Service level } \\
\text { agreement (SLA) }\left(a_{4}\right)\end{array}$ & $\begin{array}{l}\text { Service level agreements are signed between CPA } \\
\text { firms and cloud audit providers. }\end{array}$ & $\begin{array}{l}\text { Buyya et al. (2009); } \\
\text { Zhang et al. (2014); } \\
\text { Wang et al. (2016) }\end{array}$ \\
\hline \multicolumn{3}{|c|}{ Availability $(B)$} \\
\hline $\begin{array}{l}\text { Data backup and } \\
\text { disaster recovery }\left(b_{1}\right)\end{array}$ & $\begin{array}{l}\text { Cloud auditing providers provide a robust data } \\
\text { backup mechanism and disaster recovery system, } \\
\text { in order to respond to unexpected disasters. }\end{array}$ & Krishna et al. (2016) \\
\hline Data reliability $\left(b_{2}\right)$ & $\begin{array}{l}\text { Cloud auditing providers assure the data reliability } \\
\text { on the cloud, without the threat of data tempered } \\
\text { by hackers. }\end{array}$ & $\begin{array}{l}\text { Du and } \mathrm{Li}(2011) ; \\
\text { Mansouri (2016); } \\
\text { Nicolaou et al. (2012) }\end{array}$ \\
\hline $\begin{array}{l}\text { Interoperability/User } \\
\text { interfaces }\left(b_{3}\right)\end{array}$ & $\begin{array}{l}\text { Cloud auditing providers provide an interface to } \\
\text { access cloud data, and this interface is compatible } \\
\text { with the interfaces from other providers. }\end{array}$ & $\begin{array}{l}\text { Lee et al. }(2013,2015) \text {; } \\
\text { Mazalov et al. (2015) }\end{array}$ \\
\hline \multicolumn{3}{|c|}{ Processing integrity $(C)$} \\
\hline Accurate $\left(c_{1}\right)$ & $\begin{array}{l}\text { Cloud auditing providers meet the accuracy } \\
\text { requirements specified in service level agreements. }\end{array}$ & $\begin{array}{l}\text { Shkurti and Muça } \\
\text { (2014) }\end{array}$ \\
\hline $\begin{array}{l}\text { Timely/Response } \\
\text { time }\left(c_{2}\right)\end{array}$ & $\begin{array}{l}\text { Cloud auditing providers can respond to the } \\
\text { requests from CPA firms in the shortest time } \\
\text { possible. }\end{array}$ & $\begin{array}{l}\text { Tarmidi et al. (2014); } \\
\text { Yigitbasioglu (2015) }\end{array}$ \\
\hline Confirmation $\left(c_{3}\right)$ & $\begin{array}{l}\text { Cloud auditing providers can provide online } \\
\text { confirmation services that allow auditors to } \\
\text { validate the authenticity of audited data by } \\
\text { inquiring third parties (e.g. banks) for electronic } \\
\text { confirmations. }\end{array}$ & $\begin{array}{l}\text { Janvrin et al. (2010); } \\
\text { Bergh et al. (2016); } \\
\text { Axelsen et al. (2017) }\end{array}$ \\
\hline \multicolumn{3}{|c|}{ Confidentiality $(D)$} \\
\hline $\begin{array}{l}\text { Transaction details } \\
\left(d_{1}\right)\end{array}$ & $\begin{array}{l}\text { Cloud auditing providers ensure the confidentiality } \\
\text { of transaction data of companies (audit clients). }\end{array}$ & Dong et al. (2015) \\
\hline $\begin{array}{l}\text { Banking information } \\
\text { about businesses }\left(d_{2}\right)\end{array}$ & $\begin{array}{l}\text { Cloud auditing providers ensure the confidentiality } \\
\text { of dealings between companies (audit clients) and } \\
\text { banks. }\end{array}$ & $\begin{array}{l}\text { AICPA and CICA } \\
(2009)\end{array}$ \\
\hline $\begin{array}{l}\text { Revenue by client } \\
\text { and industry }\left(d_{3}\right)\end{array}$ & $\begin{array}{l}\text { Cloud auditing providers ensure the confidentiality } \\
\text { of income data of companies (audit clients). }\end{array}$ & $\begin{array}{l}\text { AICPA and CICA } \\
(2009)\end{array}$ \\
\hline
\end{tabular}


End of Table 2

\begin{tabular}{|l|l|l|}
\hline Dimensions/Criteria & \multicolumn{1}{|c|}{ Statements of criteria } & \multicolumn{1}{|c|}{ Pources } \\
\hline \multicolumn{2}{|c|}{ Privacy $(E)$} & \multicolumn{2}{|c|}{$\begin{array}{l}\text { File use/Retention/ } \\
\text { Destruction }\left(e_{1}\right)\end{array}$} & $\begin{array}{l}\text { Cloud auditing providers only retain the } \\
\text { information required to meet with the purposes set } \\
\text { forth by CPA firms or to comply with relevant laws } \\
\text { and regulations and will process such information } \\
\text { ex-post in an appropriate manner. }\end{array}$ & $\begin{array}{l}\text { AICPA and CICA } \\
(2009) ; \text { Toy and Hey } \\
(2015)\end{array}$ \\
\hline $\begin{array}{l}\text { Disclosure to third } \\
\text { parties }\left(e_{2}\right)\end{array}$ & $\begin{array}{l}\text { Cloud auditing providers can only reveal to } \\
\text { third parties the information of companies and } \\
\text { CPA firms given prior consents and for special } \\
\text { purposes. }\end{array}$ & $\begin{array}{l}\text { AICPA and CICA } \\
(2009)\end{array}$ \\
\hline $\begin{array}{l}\text { Security for privacy } \\
\left(e_{3}\right)\end{array}$ & $\begin{array}{l}\text { Cloud auditing providers should ensure to protect } \\
\text { the data privacy of the data saved by companies } \\
\text { or CPA firms on the cloud, meaning preventing } \\
\text { unauthorized access of the data. }\end{array}$ & $\begin{array}{l}\text { Gray (2008); Toy and } \\
\text { Hey (2015) }\end{array}$ \\
\hline
\end{tabular}

\section{Empirical case: cloud auditing provider adoption from the perspective of China's CPA firms}

This section describes the empirical case study of the performance evaluation and improvement model of the cloud auditing provider for China's CPA firms. Contents include five subsections: first, problem descriptions; second, constructing the IIRM by the DEMATEL Technique; third, weighting the cloud auditing provider measurement criteria based on DANP; fourth, performance evaluations among cloud auditing providers using the modified VIKOR method; fifth, discussions and implications, as follows. A diagram of the empirical case study is illustrated in Figure 3.

\subsection{Problem descriptions}

According to the schedule of the Golden Auditing Project in China, the audit model of the government will progress from onsite audits in the first phase, to online audits in the second phase, and digital audits in the third phase. This timetable is meant to keep up with the evolution of cloud audits; however, due to multiple problems, such as capital and management, the digital information of Chinese CPA firms is quite backward, and most audit works are still conducted on-site. Going forward, the future audit model and transformation of auditing informationization will enter the IoT Era of cloud auditing, and as cloud auditing becomes the mainstream, CPA firms will have to establish an open cloud for auditing procedures. Despite the commitment of cloud auditing to improve the efficiency of CPA firms, cloud auditing in China is still in its infancy. Cloud auditing leverages the benefits of cloud computing, cloud storage, and cloud services to collect Big Data from different industries and in different structures. This facilitates in-depth analytics and audit trail probing to obtain sufficient and reliable audit evidence. The high complexity of cloud auditing is a topic worthy of further exploration. Therefore, it is necessary for CPA firms to establish an assessment and improvement model to select and improve cloud auditing providers to achieve a high-quality cloud audit structure. 


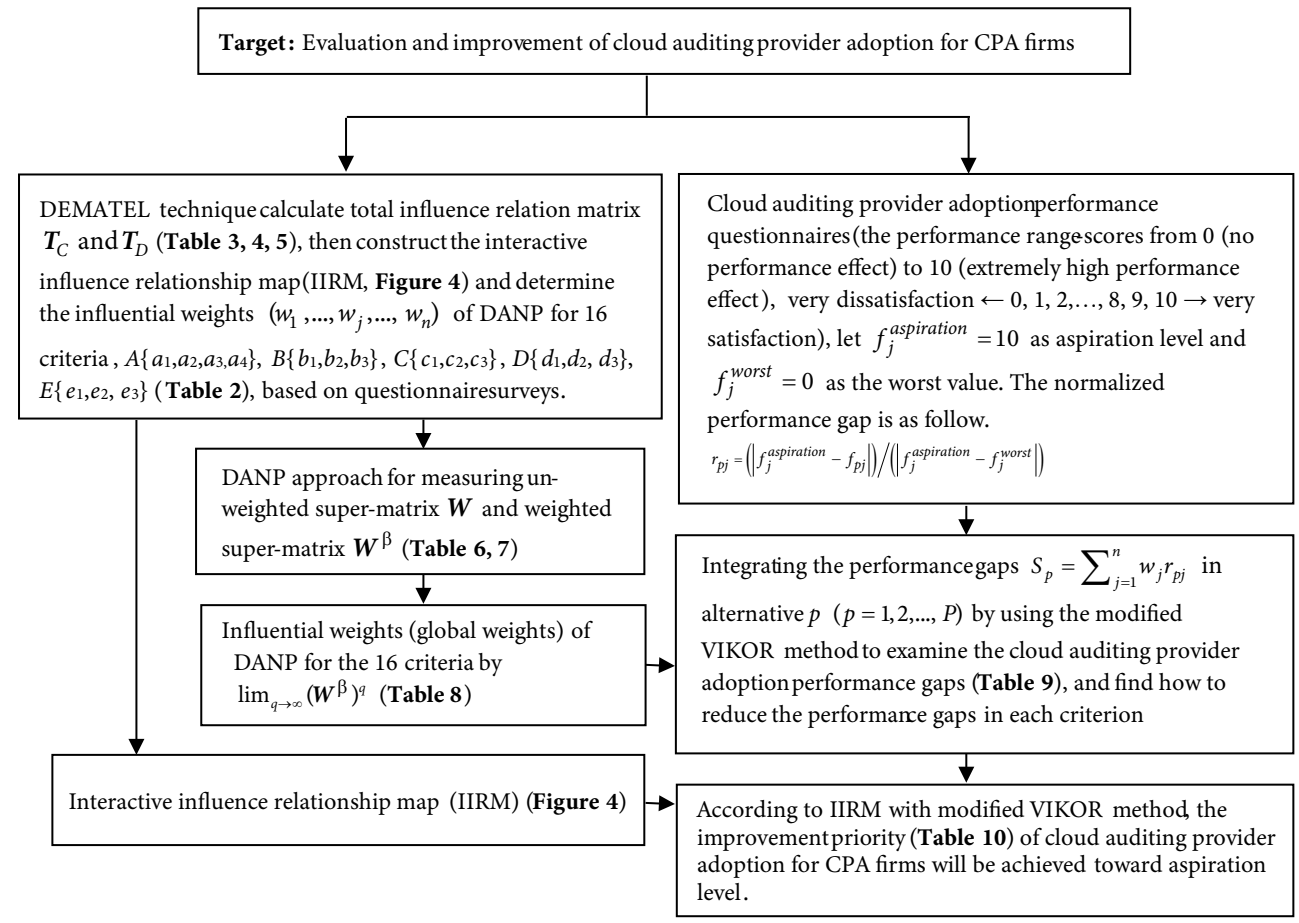

Figure 3. The process of the empirical case

\subsection{Constructing IIRM by DEMATEL Technique}

From the results of expert interviews and user questionnaire surveys, which uses 16 criteria of pairwise comparisons to obtain the average direct-influence matrix $Z$, and based on the method described in Section 4.1, there is a $16 \times 16$ matrix. The normalized direct-influence relation matrix $\boldsymbol{D}$ is calculated using Equations (A.1) and (A.2). Using Equations (A.3), (A.5), and (A.6), the total-influence relation matrix $\boldsymbol{T}_{D}$ for the dimension and $\boldsymbol{T}_{C}$ for the criteria can be deduced and used to measure the sum of the total given $r_{i}$ and received $s_{i}$ of each dimension and criterion, as shown in Tables 4 and 5, and then, IIRM is constructed using $r_{i}^{C(D)}+s_{i}^{C(D)}$ and $r_{i}^{C(D)}-s_{i}^{C(D)}$, and the influential network relationship of five dimensions and their subsystem (criteria) is shown in Figure 4. This figure can illustrate the influence relationships of all dimensions, and its criteria, within the cloud auditing provider adoption. Table 3 indicates the mutual-influence relationships of all dimensions and criteria, and the consensus of 45 respondents group achieved $98.3 \%$ in significance level (see Note in Table 3 ).

Table 3. Total influence relation matrix $\boldsymbol{T}_{C}$ : sixteen criteria

\begin{tabular}{|c|c|c|c|c|c|c|c|c|c|c|c|c|c|c|c|c|}
\hline Criteria & $a_{1}$ & $a_{2}$ & $a_{3}$ & $a_{4}$ & $b_{1}$ & $b_{2}$ & $b_{3}$ & $c_{1}$ & $c_{2}$ & $c_{3}$ & $d_{1}$ & $d_{2}$ & $d_{3}$ & $e_{1}$ & $e_{2}$ & $e_{3}$ \\
\hline$a_{1}$ & 0.236 & 0.327 & 0.257 & 0.297 & 0.246 & 0.313 & 0.258 & 0.311 & 0.276 & 0.283 & 0.294 & 0.279 & 0.267 & 0.259 & 0.266 & 0.319 \\
\hline$a_{2}$ & 0.298 & 0.242 & 0.265 & 0.296 & 0.262 & 0.311 & 0.260 & 0.304 & 0.270 & 0.276 & 0.290 & 0.266 & 0.261 & 0.248 & 0.262 & 0.306 \\
\hline$a_{3}$ & 0.248 & 0.267 & 0.177 & 0.258 & 0.223 & 0.265 & 0.240 & 0.274 & 0.246 & 0.254 & 0.245 & 0.235 & 0.228 & 0.224 & 0.239 & 0.269 \\
\hline$a_{4}$ & 0.292 & 0.310 & 0.250 & 0.241 & 0.254 & 0.311 & 0.271 & 0.325 & 0.279 & 0.291 & 0.282 & 0.263 & 0.255 & 0.257 & 0.269 & 0.300 \\
\hline
\end{tabular}


End of Table 3

\begin{tabular}{|c|c|c|c|c|c|c|c|c|c|c|c|c|c|c|c|c|}
\hline & & & & 4 & $\sigma_{1}$ & $v_{2}$ & $\sigma_{3}$ & 1 & & 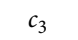 & $d_{1}$ & $a_{2}$ & $a_{3}$ & $e_{1}$ & $e_{2}$ & $e_{3}$ \\
\hline$b_{1}$ & 221 & $5=$ & 1 & 5 & 0167 & .249 & 216 & .258 & .219 & 231 & .241 & .229 & .225 & .216 & 218 & 0.252 \\
\hline$b_{2}$ & & 88 & 240 & & 51 & 2 & & & & 78 & & & & 30 & 3 & 20 \\
\hline$b_{3}$ & & & & & & & & & & & & & & & & 0.24 \\
\hline$c_{1}$ & 0200 & 305 & r & 5 & 257 & 5 & 3 & 267 & 3 & 5 & 298 & 86 & & 55 & 30 & 0.30 \\
\hline$c_{2}$ & & & & & & & & & & & & & & & & \\
\hline$c_{3}$ & & & & & & 76 & & & & & & & & & & 0.26 \\
\hline$d_{1}$ & 0264 & 0271 & 0217 & 0266 & 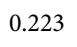 & 9 & 3 & 0.295 & 0252 & 0265 & 0 & 9 & 19 & 9 & 0.235 & ( \\
\hline$d_{2}$ & & 04 & 213 & 4 & 0. & 0.209 & $2 \angle 4$ & & t & & & 92 & & & & 0.20 \\
\hline$d_{3}$ & & & & & & 025 & 205 & 59 & & & 42 & ? & 175 & 215 & 0 & 0.25 \\
\hline$e_{1}$ & 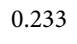 & 0.244 & 00 & 7 & 2 & 0.234 & 11 & 0 & 0 & 0.236 & 11 & 27 & 0.223 & 67 & 0.221 & 0.24 \\
\hline$e_{2}$ & & 268 & & & & 0.258 & & & 0.2 & & & & .237 & .227 & re & 0.2 \\
\hline$e_{3}$ & 339 & 349 & 287 & 338 & 0.286 & 0.352 & 0.298 & 0.360 & 0.360 & 0.330 & 0.333 & 0.307 & 0.297 & 0.292 & 0.303 & 0.27 \\
\hline
\end{tabular}

Note: Average difference-ratios in consensus $(\%)=\frac{1}{n^{2}} \sum_{i=1}^{n} \sum_{j=1}^{n}\left(\frac{\left|t_{i j}^{g}-t_{i j}^{g-1}\right|}{t_{i j}^{g}}\right) \times 100 \%=1.7 \%<5 \%$, i.e., significant confidence is $98.3 \%$, where $t_{i j}^{g}$ represents the average scores from $g$ number of experts, where $g$ is equal to 45 ; and $n$ represents the number of criteria (indicators), here $n=16$ and $n \times n$ matrix.

Table 4. Total influence relation matrix $\boldsymbol{T}_{D}$ : five Dimensions

\begin{tabular}{|cccccccccc|}
\hline Dimensions & $A$ & $B$ & $C$ & $D$ & $E$ & $\begin{array}{c}\text { Row sum } \\
\left(r_{i}^{D}\right)\end{array}$ & $\begin{array}{c}\text { Column sum } \\
\left(s_{i}^{D}\right)\end{array}$ & $r_{i}^{D}+s_{i}^{D}$ & $r_{i}^{D}-s_{i}^{D}$ \\
\hline$A$ & 0.266 & 0.268 & 0.282 & 0.264 & 0.268 & 1.349 & 1.296 & 2.644 & 0.053 \\
$B$ & 0.250 & 0.223 & 0.259 & 0.234 & 0.235 & 1.201 & 1.240 & 2.441 & -0.039 \\
$C$ & 0.265 & 0.262 & 0.269 & 0.259 & 0.254 & 1.390 & 1.346 & 2.655 & -0.037 \\
$D$ & 0.246 & 0.234 & 0.258 & 0.127 & 0.240 & 1.104 & 1.147 & 2.251 & -0.042 \\
$E$ & 0.269 & 0.254 & 0.278 & 0.262 & 0.244 & 1.307 & 0.883 & 2.190 & 0.424 \\
\hline
\end{tabular}

Table 5 shows that, of the five dimensions, privacy $(\boldsymbol{E})$ has the highest difference $r_{i}^{D}-s_{i}^{D}$ $\left(r_{i}^{D}-s_{i}^{D}=0.424\right)$ in influence relationship, which indicates that this dimension had the strongest impact, and is affected other dimensions, and therefore, should be considered more important than other cloud auditing provider adoption dimensions for CPA firms. While, confidentiality $(\boldsymbol{D})$ shows the smallest $r_{i}^{D}-s_{i}^{D}$ value $\left(r_{i}^{D}-s_{i}^{D}=-0.042\right)$.

Table 5 also indicates the influential relationship of each criterion. In the criteria assessment of cloud auditing provider adoption for CPA firms, "security for privacy $\left(e_{3}\right)$ " has the largest $r_{i}^{C}-s_{i}^{C}$ value among all the criteria (with maximal $r_{i}^{C}-s_{i}^{C}=0.077$ ), showing that this criterion has the largest direct and indirect impacts on other criteria (indicators). However, "file use/retention/destruction $\left(e_{1}\right)$ " is most easily influenced by other criteria (with minimal $r_{i}^{C}-s_{i}^{C}=-0.05$ ); this significant relationship is also obvious among the five dimensions. The $r_{i}^{C}-s_{i}^{C}$ values of security and privacy are positive, which confirms their direct effect on other dimensions. On the other hand, processing integrity $(C)$, availability $(B)$, and confidentiality $(D)$ are negative, meaning these three dimensions are influenced by other dimensions (Pri$\operatorname{vacy}(E)$ and Security $(A))$. 
Table 5. The sum of the influences (given and received) on the core dimensions and criteria

\begin{tabular}{|lcccc|}
\hline \multicolumn{1}{|c}{ Dimensions/Criteria } & $\begin{array}{c}\text { Row sum } \\
\left(r_{i}^{C}\right)\end{array}$ & $\begin{array}{c}\text { Column sum } \\
\left(s_{i}^{C}\right)\end{array}$ & $r_{i}^{C}+s_{i}^{C}$ & $r_{i}^{C}-s_{i}^{C}$ \\
\hline Security $(\boldsymbol{A})$ & $\mathbf{1 . 3 4 9}$ & $\mathbf{1 . 2 9 6}$ & $\mathbf{2 . 6 4 4}$ & $\mathbf{0 . 0 5 3}$ \\
Access control \& privilege management $\left(a_{1}\right)$ & 1.118 & 1.074 & 2.192 & 0.043 \\
Physical security \& logical security $\left(a_{2}\right)$ & 1.101 & 1.147 & 2.249 & -0.046 \\
Data Geographic/Political $\left(a_{3}\right)$ & 0.950 & 0.949 & 1.899 & 0.001 \\
Service level agreement $(\mathrm{SLA})\left(a_{4}\right)$ & 1.093 & 1.092 & 2.185 & 0.002 \\
Availability $(\boldsymbol{B})$ & $\mathbf{1 . 2 0 1}$ & $\mathbf{1 . 2 4 0}$ & $\mathbf{2 . 4 4 1}$ & $-\mathbf{0 . 0 3 9}$ \\
Data backup and disaster recovery $\left(b_{1}\right)$ & 0.633 & 0.639 & 1.272 & -0.006 \\
Data reliability $\left(b_{2}\right)$ & 0.732 & 0.727 & 1.459 & 0.005 \\
Interoperability/User interfaces $\left(b_{3}\right)$ & 0.644 & 0.643 & 1.287 & 0.001 \\
Processing integrity $(\boldsymbol{C})$ & $\mathbf{1 . 3 0 9}$ & $\mathbf{1 . 3 4 6}$ & $\mathbf{2 . 6 5 5}$ & $\mathbf{- 0 . 0 3 7}$ \\
Accuracy $\left(c_{1}\right)$ & 0.885 & 0.846 & 1.731 & 0.039 \\
Timely/Response time $\left(c_{2}\right)$ & 0.767 & 0.766 & 1.533 & 0.001 \\
Confirmation $\left(c_{3}\right)$ & 0.765 & 0.804 & 1.569 & -0.039 \\
Confidentiality $(\boldsymbol{D})$ & $\mathbf{1 . 1 0 4}$ & $\mathbf{1 . 1 4 7}$ & $\mathbf{2 . 2 5 1}$ & $\mathbf{- 0 . 0 4 2}$ \\
Transaction details $\left(d_{1}\right)$ & 0.707 & 0.706 & 1.414 & 0.001 \\
Banking information about businesses $\left(d_{2}\right)$ & 0.684 & 0.667 & 1.351 & 0.017 \\
Revenue by client and industry $\left(d_{3}\right)$ & 0.643 & 0.661 & 1.304 & -0.018 \\
Privacy $(\boldsymbol{E})$ & $\mathbf{1 . 3 0 7}$ & $\mathbf{0 . 8 3 3}$ & $\mathbf{2 . 1 9 0}$ & $\mathbf{0 . 4 2 4}$ \\
File use/Retention/Destruction $\left(e_{1}\right)$ & 0.637 & 0.686 & 1.323 & -0.050 \\
Disclosure to third parties $\left(e_{2}\right)$ & 0.685 & 0.712 & 1.397 & -0.027 \\
Security for privacy $\left(e_{3}\right)$ & 0.872 & 0.795 & 1.667 & 0.077 \\
\hline
\end{tabular}

\subsection{Weighting the cloud auditing provider measurement criteria based on DANP}

In Stage 2, integrating the DEMATEL technique into the ANP concept will simultaneously determine the influential weights of DANP, as extracted from the dynamic relationships among the criteria. Thus, the cloud auditing provider adoption assessment model for CPA firms is created using DANP to determine the IWs of each criterion. Based on the DEMATEL technique, the unweighted super-matrix $\boldsymbol{W}$ (Table 6) from Equations (A.10-A.12) and the weighted super-matrix $W^{\beta}$ (Table 7) from Equations (A.8) and (A.14-A.15) could be derived. The global weights of the criteria could be obtained by using limiting power to the super-weighted matrix $\lim _{q \rightarrow \infty}\left(W^{\beta}\right)^{q}$ and obtaining a long-term stable condition, as presented in Table 8. Thereafter, the IWs (also called "global weights") of DANP can be converted to the local weights of the assessment criteria in each dimension, and be applied to use the modified VIKOR to further integrate the performance gap ratio $r_{p j}=\left(\left|f_{j}^{\text {aspiration }}-f_{p j}\right|\right) /\left(\left|f_{j}^{\text {aspiration }}-f_{j}^{\text {worst }}\right|\right)$ from each criterion into the dimensions, as well as the overall assessment. 


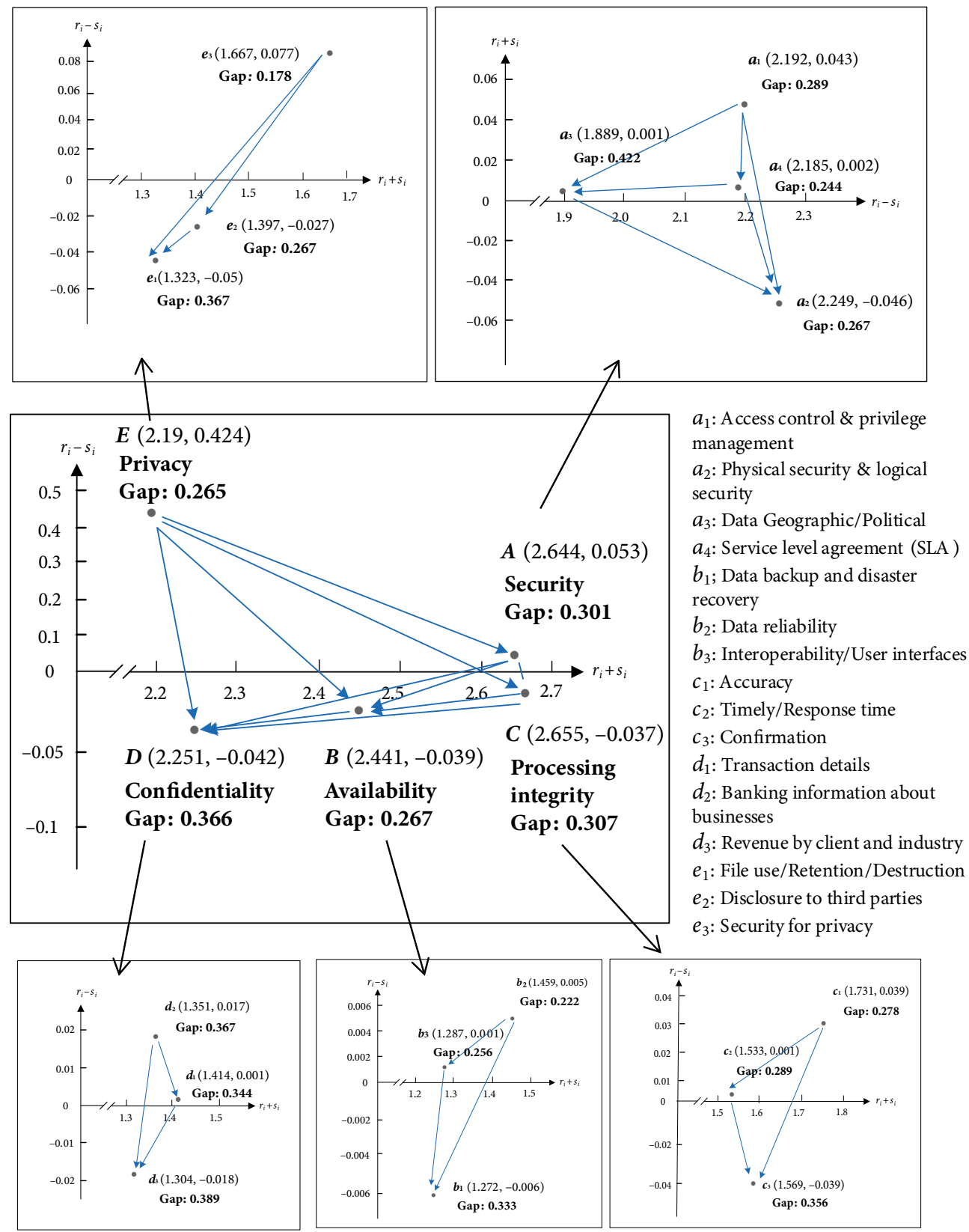

Figure 4 . The IIRM of influence relationships within the cloud auditing provider adoption 
Table 6. Un-weighted super-matrix $\boldsymbol{W}=\left(\boldsymbol{T}_{C}^{\beta}\right)^{\prime}$ for CPA firm's cloud auditing provider adoption criteria

\begin{tabular}{|ccccccccccccccccc|}
\hline Criteria & $a_{1}$ & $a_{2}$ & $a_{3}$ & $a_{4}$ & $b_{1}$ & $b_{2}$ & $b_{3}$ & $c_{1}$ & $c_{2}$ & $c_{3}$ & $d_{1}$ & $d_{2}$ & $d_{3}$ & $e_{1}$ & $e_{2}$ & $e_{3}$ \\
\hline$a_{1}$ & 0.211 & 0.271 & 0.261 & 0.267 & 0.246 & 0.257 & 0.245 & 0.254 & 0.249 & 0.250 & 0.259 & 0.258 & 0.256 & 0.254 & 0.253 & 0.258 \\
$a_{2}$ & 0.293 & 0.220 & 0.281 & 0.284 & 0.269 & 0.264 & 0.260 & 0.259 & 0.256 & 0.259 & 0.266 & 0.264 & 0.265 & 0.266 & 0.267 & 0.266 \\
$a_{3}$ & 0.230 & 0.241 & 0.186 & 0.229 & 0.225 & 0.220 & 0.222 & 0.220 & 0.221 & 0.221 & 0.213 & 0.213 & 0.218 & 0.222 & 0.219 & 0.219 \\
$a_{4}$ & 0.266 & 0.268 & 0.271 & 0.220 & 0.261 & 0.259 & 0.273 & 0.267 & 0.274 & 0.270 & 0.262 & 0.265 & 0.262 & 0.258 & 0.260 & 0.257 \\
$b_{1}$ & 0.301 & 0.314 & 0.306 & 0.303 & 0.265 & 0.343 & 0.342 & 0.300 & 0.308 & 0.306 & 0.303 & 0.305 & 0.306 & 0.312 & 0.307 & 0.306 \\
$b_{2}$ & 0.383 & 0.374 & 0.364 & 0.372 & 0.394 & 0.317 & 0.382 & 0.381 & 0.371 & 0.366 & 0.380 & 0.380 & 0.382 & 0.362 & 0.368 & 0.376 \\
$b_{3}$ & 0.316 & 0.312 & 0.330 & 0.325 & 0.341 & 0.340 & 0.276 & 0.319 & 0.321 & 0.328 & 0.317 & 0.315 & 0.312 & 0.326 & 0.325 & 0.318 \\
$c_{1}$ & 0.357 & 0.358 & 0.354 & 0.363 & 0.364 & 0.358 & 0.356 & 0.302 & 0.380 & 0.376 & 0.363 & 0.356 & 0.361 & 0.362 & 0.359 & 0.359 \\
$c_{2}$ & 0.317 & 0.317 & 0.328 & 0.312 & 0.309 & 0.315 & 0.312 & 0.342 & 0.260 & 0.345 & 0.310 & 0.311 & 0.304 & 0.309 & 0.308 & 0.311 \\
$c_{3}$ & 0.325 & 0.325 & 0.346 & 0.325 & 0.327 & 0.327 & 0.331 & 0.356 & 0.360 & 0.278 & 0.326 & 0.333 & 0.335 & 0.329 & 0.333 & 0.329 \\
$d_{1}$ & 0.350 & 0.355 & 0.332 & 0.353 & 0.347 & 0.355 & 0.350 & 0.348 & 0.350 & 0.348 & 0.296 & 0.372 & 0.377 & 0.349 & 0.351 & 0.356 \\
$d_{2}$ & 0.332 & 0.325 & 0.322 & 0.238 & 0.330 & 0.324 & 0.328 & 0.333 & 0.326 & 0.334 & 0.352 & 0.281 & 0.351 & 0.328 & 0.324 & 0.328 \\
$d_{3}$ & 0.318 & 0.320 & 0.226 & 0.319 & 0.324 & 0.321 & 0.322 & 0.319 & 0.324 & 0.318 & 0.352 & 0.347 & 0.272 & 0.323 & 0.325 & 0.317 \\
$e_{1}$ & 0.307 & 0.304 & 0.306 & 0.311 & 0.315 & 0.304 & 0.308 & 0.311 & 0.316 & 0.307 & 0.312 & 0.308 & 0.311 & 0.262 & 0.332 & 0.336 \\
$e_{2}$ & 0.315 & 0.321 & 0.327 & 0.326 & 0.318 & 0.322 & 0.327 & 0.328 & 0.331 & 0.326 & 0.320 & 0.326 & 0.318 & 0.347 & 0.275 & 0.347 \\
$e_{3}$ & 0.378 & 0.374 & 0.367 & 0.363 & 0.367 & 0.374 & 0.365 & 0.362 & 0.352 & 0.367 & 0.368 & 0.367 & 0.370 & 0.391 & 0.394 & 0.317 \\
\hline
\end{tabular}

Table 7. Weighted super-matrix $\boldsymbol{W}^{\beta}=\boldsymbol{T}_{D}^{\beta} \boldsymbol{W}$ for CPA firm's cloud auditing provider adoption elements

\begin{tabular}{|c|c|c|c|c|c|c|c|c|c|c|c|c|c|c|c|c|}
\hline Criteria & $a_{1}$ & $a_{2}$ & $a_{3}$ & $a_{4}$ & $b_{1}$ & $b_{2}$ & $b_{3}$ & $c_{1}$ & $c_{2}$ & $c_{3}$ & $d_{1}$ & $d_{2}$ & $d_{3}$ & $e_{1}$ & $e_{2}$ & $e_{3}$ \\
\hline$a_{1}$ & 052 & 0.067 & .065 & 0.066 & 064 & 0.067 & 0.064 & .064 & 0.063 & 0.063 & 0.066 & .066 & 0.065 & 0.065 & 0.065 & 0.066 \\
\hline$a_{2}$ & 0.072 & 0.054 & 0.069 & 0.070 & 0.070 & 0.068 & 0.067 & 0.065 & 0.065 & 0.066 & 0.068 & 0.067 & 0.067 & 0.068 & 0.069 & 0.068 \\
\hline$a_{3}$ & 57 & 060 & 046 & 056 & 0.058 & 0.057 & 057 & 056 & 0.056 & 0.056 & 0.054 & 0.054 & 0.055 & .057 & .056 & .056 \\
\hline$a_{4}$ & .066 & 0.066 & 0.067 & 054 & 0.068 & 0.067 & 0.071 & 0.067 & 0.069 & 0.068 & 0.067 & 0.067 & 0.067 & 0.066 & 0.067 & 0.066 \\
\hline$b_{1}$ & 0.056 & 0.059 & 0.057 & 0.057 & 0.046 & 0.060 & 0.059 & 0.056 & 0.058 & 0.057 & 0.055 & 0.055 & 0.056 & 0.057 & 0.056 & 0.056 \\
\hline$b_{2}$ & 7 & 070 & 068 & 069 & 068 & 0.055 & 0.066 & 071 & .070 & 0.069 & 0.069 & 0.069 & 0.069 & 0.066 & 067 & .058 \\
\hline$b_{3}$ & 0.059 & 0.058 & 0.061 & 0.061 & 0.059 & 0.059 & 0.048 & 0.060 & 0.060 & 0.062 & 0.058 & 0.057 & 0.057 & 0.059 & 0.059 & 0.072 \\
\hline$c_{1}$ & 0.070 & 0.070 & 0.070 & 0.071 & 0.073 & 0.072 & 0.072 & .058 & 0.073 & 0.072 & 0.073 & 0.071 & 0.073 & 0.072 & 0.072 & 0.062 \\
\hline$c_{2}$ & 0062 & 0.062 & 0062 & 006 & 0.062 & 0.063 & 0.063 & 0.066 & 0.050 & 0.066 & 0.062 & 0.063 & 0.061 & 0.062 & 0.061 & 0.061 \\
\hline$c_{3}$ & 064 & 0064 & 0.064 & 064 & 0.066 & 0.066 & 0.067 & 0.068 & 0.069 & 0.054 & 0.066 & 0.067 & 0.067 & 0.066 & 0.066 & 0.066 \\
\hline$d_{1}$ & 0.064 & 0.065 & 0.064 & 0.065 & 0.063 & 0.065 & 0.064 & 0.065 & 0.065 & 0.065 & 0.052 & 0.065 & 0.066 & 0.065 & 0.066 & 0.067 \\
\hline$d_{2}$ & 0.001 & 0.060 & 0.061 & 0.060 & 0 & 0.0 & 0.060 & 0.062 & 1 & 0.066 & 0.062 & 0.049 & 0.062 & .062 & 0.061 & 0.06 \\
\hline$d_{3}$ & 0.058 & 0.059 & 0059 & 0.0 & 0.059 & 0.059 & 0.059 & 0.059 & 0.060 & 0059 & 0.062 & 0.061 & 0.048 & 060 & 0.061 & 0.059 \\
\hline$e_{1}$ & 0.057 & 0.057 & 0.057 & 0.058 & 0.058 & 0.56 & 0.056 & 0.057 & 0.058 & 0.056 & 0.058 & 0.057 & 0.058 & 0.046 & 0.058 & 0.059 \\
\hline$e_{2}$ & 0.059 & 0.060 & 0.061 & 0.061 & 0.058 & 0.059 & 0.060 & 0.060 & 0.060 & 0.059 & 0.060 & 0.061 & 0.059 & 0.061 & .048 & .061 \\
\hline$e_{3}$ & 0.071 & 0.070 & 0.069 & 0.068 & 0.067 & 0.068 & 0.067 & 0.066 & 0.064 & 0.067 & 0.069 & 0.068 & 0.069 & 0.068 & 0.069 & 0.055 \\
\hline
\end{tabular}

Table 8. Influential weights of DANP for each criterion obtained by $\lim _{q \rightarrow \infty}\left(\boldsymbol{W}^{\beta}\right)^{q}$

\begin{tabular}{|c|c|c|c|c|c|c|c|c|c|c|c|c|c|c|c|c|}
\hline Criteria & $a_{1}$ & $a_{2}$ & $a_{3}$ & $a_{4}$ & $b_{1}$ & $b_{2}$ & $b_{3}$ & $c_{1}$ & $c_{2}$ & $c_{3}$ & $d_{1}$ & $d_{2}$ & $d_{3}$ & $e_{1}$ & $e_{2}$ & $e_{3}$ \\
\hline $\begin{array}{l}\text { Weights } \\
\text { (DANP) }\end{array}$ & 0.064 & 0.067 & 0.056 & 0.066 & 0.056 & 0.068 & 0.058 & 0.071 & 0.062 & 0.065 & 0.064 & 0.060 & 0.059 & 0.057 & 0.059 & 0.067 \\
\hline
\end{tabular}




\subsection{Performance evaluations among cloud auditing providers using the modified VIKOR method}

The modified VIKOR method can be used to assess the overall performance gap ratio and propose the best performance improvement strategies for the adoption of cloud auditing providers for CPA firms toward achieving the aspiration level. The global weights (influential weights of DANP) are multiplied by gap ratio $\left(r_{p j}\right)$, thus, obtaining the score ratio of each criterion and total average gap ratio $\left(s_{p}=\sum_{j=1}^{n} w_{j} r_{p j}\right.$ in alternative $\left.p\right)$ in CPA firms' cloud auditing provider adoption. Accordingly, from each performance score $f_{p j}$ in the $j$ th criterion of the $p$ th alternative, where $j=1,2, \ldots, n, p=1,2, \ldots, P$, as well as the corresponding $j$ th criterion gap ratio $r_{p j}=\left(\left|f_{j}^{\text {aspiration }}-f_{p j}\right|\right) /\left(\left|f_{j}^{\text {aspiration }}-f_{j}^{\text {worst }}\right|\right)$ in alternative $p$, the total average performance score can be derived, as shown in Table 9. According to the total performance score in $n$ criteria, decision-makers can determine problem-solutions and develop the best performance improvement strategies toward achieving the aspiration level.

In terms of criteria regarding how to improve the performance gap, and which criteria should be given priority for improvement to achieve the aspiration level in our real case, the recommended results are prioritized by considering the performance scores from low to high and the gap scores from high to low. Data Geographic/Political $\left(a_{3}\right)$ exhibits the lowest performance score of 5.78, as well as the highest gap score ratio of 0.422 , and this criterion is also influenced by the related second highest gap (0.289) of access control and privilege management $\left(a_{1}\right)$, as well as the lowest gap (0.244) of service level agreement (SLA) $\left(a_{4}\right)$, meaning that this criterion should be given priority for improvement, as based on IIRM by systematics; if these criteria in the security $A$ dimension are improved, dimensions $C, B$, and $D$ are also improved (see Tables $4-5$ and Figure 4 ). In terms of dimensions, confidentiality $(D)$ demonstrates the highest gap score ratio of 0.366 , while privacy $(E)$ receives the lowest gap score ratio of 0.265 , meaning that, while confidentiality $(D)$ should be improved first, Dimension $D$ will also be affected by the simultaneous improvements of dimensions $E \rightarrow A \rightarrow C \rightarrow B$. The total average performance is 6.99, which implies that the total average aspiration gap expressing room for improvement is 0.301 , and its distance from the optimum level is $30.1 \%$.

\subsection{Discussions and Implications}

DEMATEL technology allow us to demonstrate IIRM, as shown in Figure 4, which illustrates the causal relationships among the systems (dimensions) and sub-systems (criteria) for assessing cloud auditing provider adoption for CPA firms. According to the magnitude of the influence relationship, the priority of dimensions for improvement is: privacy $(E)$, security $(A)$, processing integrity $(C)$, Availability $(B)$, and confidentiality $(D)$. The results also indicate that privacy $(E)$ shows the most significant and straightforward network influence relationship on other dimensions, which can simultaneously help solve the problems of having multiple and conflicting objectives. In each dimension, some of the criteria also reveal the same network effect, such as access control and privilege management $\left(a_{1}\right)$, data reliability $\left(b_{2}\right)$, accuracy $\left(c_{1}\right)$, banking information about businesses $\left(d_{2}\right)$, and security for privacy $\left(e_{3}\right)$. 
Table 9. Performance scores of CPA firm's cloud auditing provider adoption dimensions and criteria

\begin{tabular}{|c|c|c|c|c|}
\hline & $\begin{array}{c}\text { Local } \\
\text { weights }\end{array}$ & $\begin{array}{c}\text { Global } \\
\text { weights }\end{array}$ & Performance & $\begin{array}{c}\text { Gaps } \\
\left(r_{p j}\right)\end{array}$ \\
\hline Security $(A)$ & 0.253 & & 6.99 & $0.301(3)$ \\
\hline Access control \& privilege management $\left(a_{1}\right)$ & 0.253 & 0.064 & 7.11 & 0.289 \\
\hline Physical security \& logical security $\left(a_{2}\right)$ & 0.265 & 0.067 & 7.33 & 0.267 \\
\hline Data Geographic/Political $\left(a_{3}\right)$ & 0.220 & 0.056 & 5.78 & 0.422 \\
\hline Service level agreement (SLA) $\left(a_{4}\right)$ & 0.262 & 0.066 & 7.56 & 0.244 \\
\hline Availability $(B)$ & ${ }^{\mathrm{a}} \mathbf{0 . 1 8 3}$ & & 7.33 & $0.267(4)$ \\
\hline Data backup and disaster recovery $\left(b_{1}\right)$ & $\mathrm{b}_{0} 0.308$ & 0.056 & 6.67 & 0.333 \\
\hline Data reliability $\left(b_{2}\right)$ & 0.372 & 0.068 & 7.78 & 0.222 \\
\hline Interoperability/User interfaces $\left(b_{3}\right)$ & 0.320 & 0.059 & 7.44 & 0.256 \\
\hline Processing integrity $(C)$ & 0.198 & & 6.93 & $0.307(2)$ \\
\hline Accuracy $\left(c_{1}\right)$ & 0.358 & 0.071 & 7.22 & 0.278 \\
\hline Timely/Response time $\left(c_{2}\right)$ & 0.313 & 0.062 & 7.11 & 0.289 \\
\hline Confirmation $\left(c_{3}\right)$ & 0.329 & 0.065 & 6.44 & 0.356 \\
\hline Confidentiality $(D)$ & 0.183 & & 6.34 & $0.366(1)$ \\
\hline Transaction details $\left(d_{1}\right)$ & 0.350 & 0.064 & 6.56 & 0.344 \\
\hline Banking information about businesses $\left(d_{2}\right)$ & 0.329 & 0.060 & 6.33 & 0.367 \\
\hline Revenue by client and industry $\left(d_{3}\right)$ & 0.321 & 0.059 & 6.11 & 0.389 \\
\hline Privacy $(E)$ & 0.183 & & 7.35 & $0.265(5)$ \\
\hline File use/Retention/Destruction $\left(e_{1}\right)$ & 0.310 & 0.057 & 6.33 & 0.367 \\
\hline Disclosure to third parties $\left(e_{2}\right)$ & 0.323 & 0.059 & 7.33 & 0.267 \\
\hline Security for privacy $\left(e_{3}\right)$ & 0.367 & 0.067 & 8.22 & 0.178 \\
\hline Total performance & & & 6.99 & \\
\hline Total gap ratio $\left(S_{k}\right)$ & & & & 0.301 \\
\hline
\end{tabular}

Notes: ${ }^{\text {a }}$ For Example, the local weights calculations from global weights: the availability $(B): 0.183=$ $0.056+0.068+0.059 ;{ }^{b}$ the data backup and disaster recovery $\left(b_{1}\right): 0.308=0.056 \div(0.056+0.068+$ $0.059)$.

Table 9 illustrates the gap between the performance score of each dimension and criterion, as well as the aspiration level (was 10). Table 9 also indicates that the aggregate performance score is 6.99 and the overall average gap is 0.301 , meaning there is still room for improvement. The gap values, in decreasing order of the five dimensions, are $D, C_{-} \_A$, $\_B, \_$. The dimension of confidentiality $(D)$, which has the lowest performance score (only 6.34) and the highest gap score (reach 0.366 ), should be the first priority for improvement in terms of the gap values of each dimension if CPA firms/auditors attempt to obtain the best provider improvements for reaching the aspiration level in the overall systems. From another viewpoint, CPAs lack confidence in the confidentiality $(D)$ dimension, implying that cloud providers still do not have complete confidentiality of client information in the cloud in China. The results also show that it is most difficult to achieve the aspiration level for maintaining "confidentiality", because CPA firms believe that the potential risk in allowing a cloud 
auditing provider to own and operate the firm's and their clients' data would be beyond their control. Whether the provider can accomplish "confidentiality" is the most important basis for CPA firms in selecting cloud auditing providers. The privacy $(E)$ dimension exhibits the highest performance and the lowest gap value among the dimensions, which reveals that the dimension is considered to have a high degree of confidence, receiving almost unanimous support for CPAs. However, the lowest gap score is associated with the optimal scale for the dimension of "privacy" among the dimensions, indicating that it is easier for decision-makers to improve. Yu, Xiao, and Zhang (2016) noted that China's central government has developed a cloud computing ecosystem that is of great concern to the data privacy of domestic cloud providers in providing cloud services to improve service trustworthiness and have relatively good performance. The results are also consistent with the view of AICPA/CICA; that is, they have developed guidance rules based on GAPP (Generally Accepted Privacy Principles) to assist organizations to maintain the best practices of "privacy", and to indicate that corporate "privacy" compliance is exceedingly focused.

Among the 16 criteria (Table 9) in the CPA firm's cloud auditing provider adoption factor assessment model, the data of geography/politics shows the largest gap score, which means that it has the least satisfaction. If a firm's and clients' data are stored in another country or region, data jurisdictions become significantly more complicated, which is also a pronounced concern for CPA firms. The jurisdiction of courts could affect how to address disputes concerning data, thus, managing the ability of cloud auditing providers for data of transcending geographical and political boundaries tends to impede cloud auditing adoption by CPA firms. Although they want to maintain control of their data, many could not provide an affirmative answer of how to reach this goal. Consequently, providers must offer a solution for improving data sovereignty, in order to help ease operational jurisdiction concerns. In summary, CPAs can exhaustively determine the most important influential factors in evaluating cloud auditing providers, and obtain the best their selection and improvement strategies toward achieving the aspiration level accordingly.

Cloud auditing can greatly enhance the competitiveness of China's small and mediumsized CPA firms. Compared with Big 4 CPA firms, China's small and medium-sized CPA firms lack the competitiveness and it is mostly because the auditing resources and technical support of software are insufficient. The data and resources under the cloud auditing and the development and maintenance of software are all provided by the third party cloud provider, which has reduced the threshold of China's small and medium-sized CPA firms to obtain the same advanced technology as Big 4 CPA firms and hence enhanced the market competitiveness of China's small and medium-sized CPA firms. At the same time, the auditing procedures in the cloud audit process are provided by the third party, consequently reducing the possibility of the auditors' subjective choice for auditing procedures and improving the objectivity of auditing work. Therefore, the cloud auditing is a major change of the IT auditing method in the CPA firms, which can promote the effectiveness and competitiveness of audit scale.

Therefore, the cloud auditing provider selection for CPA firms should establish perfect planning for the continuous improvement and sustainable development of their audit services toward achieving the aspiration level. However, the adoption factor improvements for 
cloud auditing providers is the axis of sustainable development. This point of view is clearly indicated in Table 10, which shows that our results prioritize the improvements of each dimension, as well as their criterion, in the assessment framework of cloud auditing providers' adoption, in order to achieve the goal of this study.

Table 10. The CPA firm's cloud auditin provider adoption improvement strategy

\begin{tabular}{|ll|}
\hline \multicolumn{1}{|c|}{ Items } & Strategy (improvement priority based on gap value from high to low) \\
\hline $\begin{array}{l}\text { I1: Sequence of dimensions } \\
\text { to achieve aspiration }\end{array}$ & $D_{-} C_{-} A_{-} B_{-} E$ \\
level & \\
I2: Sequence of criteria & $A:\left(a_{3}\right)_{-}\left(a_{1}\right)_{-}\left(a_{2}\right)-\left(a_{4}\right)$ \\
to achieve aspiration & $B:\left(b_{1}\right)-\left(b_{3}\right)_{-}\left(b_{2}\right)$ \\
level within individual & $C:\left(c_{3}\right)_{-}\left(c_{2}\right)-\left(c_{1}\right)$ \\
dimensions & $D:\left(d_{3}\right)_{-}\left(d_{2}\right)-\left(d_{1}\right)$ \\
& $E:\left(e_{1}\right)_{-}\left(e_{2}\right)_{-}\left(e_{3}\right)$ \\
\hline
\end{tabular}

Notes: 1. Dimensions: Security $(A)$, Availability $(B)$, Processing integrity $(C)$, Confidentiality $(D)$, Privacy $(E)$. 2. Criteria: Access control \& privilege management $\left(a_{1}\right)$, Physical security \& logical security $\left(a_{2}\right)$, Data Geographic/Political $\left(a_{3}\right)$, Service level agreement (SLA) $\left(a_{4}\right)$, Data backup and disaster recovery $\left(b_{1}\right)$, Data reliability $\left(b_{2}\right)$, Interoperability/User interfaces $\left(b_{3}\right)$, Accuracy $\left(c_{1}\right)$,Timely/Response time $\left(c_{2}\right)$, Confirmation $\left(c_{3}\right)$, Transaction details $\left(d_{1}\right)$, Banking information about businesses $\left(d_{2}\right)$, Revenue by client and industry $\left(d_{3}\right)$, File use/retention/destruction $\left(e_{1}\right)$, Disclosure to third parties $\left(e_{2}\right)$, and Security for privacy $\left(e_{3}\right)$.

\section{Conclusion and remarks}

The current big data is accompanied with cloud computing and IoT, and it is having a huge impact on the global economy and society, and provides new technologies and methods for modern auditing industry and changes the thinking and technique of contemporary auditing, and promotes the big data' auditing development. This study proposed a hybrid MADM model for the adoption of cloud auditing providers for CPA firms. The improved strategies, as proposed in the cloud-based environment on an auditing platform, offer a reference for CPA firms in choosing the best cloud auditing providers. The hybrid decision model constructed herein integrated the DEMATEL technique, IIRM, DANP, and modified VIKOR, and refined the relationships among the factors/criteria/indicators. The DEMATEL technique was employed to construct IIRM, which illustrates the influential network of the cloud computing provider evaluation and improvement model. The DANP (DEMATEL-based ANP) approach was used to calculate the influential weights of criteria to overcome the problems of the interdependence and feedback relationships among the dimensions, criteria, and alternatives. The modified VIKOR ("aspiration-worst" replace traditional "max-min" as benchmark) was used to assess and improve the total performance of cloud auditing providers, in order to detect the performance values and gaps toward achieving the aspiration level.

According to the opinions of domain experts, the security of privacy was regarded as the most important consideration among in the 16 criteria, as it is most likely to affect other criteria/factors due to its decisive role in CPA firm's cloud auditing provider selection. Compared to past studies, and based on the solution of this model, decision-making strategies have improved. This research makes decisions by simultaneously considering 
the performance gap of each indicator and their interactive influence relationship. Thus, according to the results of this paper, the decision making process is shown, as follows: The dimension gap scores for improvement consideration are: confidentiality $(D$, affected the largest gap: 0.366$)$ is a priority improvement, at the same time, processing integrity $(C$, affected the next largest gap: 0.306$)$ and security ( $A$, affected the third largest gap: 0.301) must also be considered for improvement, availability ( $B$, gap: 0.267 ), and privacy ( $E$, gap: 0.265 , affect $A \rightarrow C \rightarrow B \rightarrow D$ ). The improvement plan should be implemented based on the priority order, starting with the largest gap (confidentiality $(D)$ ), and those that affect other sources $(E \rightarrow A \rightarrow C \rightarrow B \rightarrow D)$, in order to provide a sound cloud auditing environment for CPA firms making the best improvement strategies, as based on the systematics of IIRM. The intricate relationship of cloud auditing provider adoption can be clarified using the research methods discussed herein. Moreover, this study provides a general evaluation and improvement framework for small and medium-sized accounting firms in China to adopt cloud auditing providers, and can be a reference for providers to design a cloud-based auditing model for CPA firms. The comparison table about the pros and cons of the simultaneously considering performance gap and interactive influence relationship is shown in Table 11.

Although this study has developed an empirical evaluation model, there are some interesting ideas worthy of further examination by future research. The proposed evaluation framework in this study is based on the SOC of AICPA, and expert opinions may not be considered very comprehensive. At present, because of a large number of cloud auditing providers and the uneven quality of the providers in China, the cloud auditing is still at the stage of development and it is difficult to find a representative cloud auditing provider. Moreover, cloud auditing providers have different backgrounds, benchmarks and business model; there

Table 11. The comparison on the pros and cons of simultaneously considering performance gap and interactive influence relationship

\begin{tabular}{|c|c|}
\hline Improvement strategy & The pros and cons \\
\hline $\begin{array}{l}\text { Priority is given to } \\
\text { improving those with } \\
\text { larger performance gaps } \\
\text { and the same time the } \\
\text { interactive influence } \\
\text { relationship between the } \\
\text { indicators should } \\
\text { be considered } \\
\text { (based on modified } \\
\text { VIKOR and DEMATEL) }\end{array}$ & $\begin{array}{l}\text { 1. Decisions are made simultaneously according to the interactive } \\
\text { influence relationship of indicators, as obtained by the DEMATEL } \\
\text { technique, and the performance of each indicator measured by } \\
\text { modified VIKOR } \\
\text { 2. Which can achieve the synergy effect in improvement strategies and } \\
\text { fulfill "problem-solving and improvement" } \\
\text { 3. Systematic performance improvement toward reaching the aspiration } \\
\text { level to avoid "stop-gap piecemeal" } \\
\text { 4. Using a systematic approach to address the problems from the root } \\
\text { and can build the integrity (overall-view) of improvement strategies } \\
\text { 5. The relative good solution from the existing alternatives is replaced } \\
\text { by the aspiration levels to fit today's competitive markets } \\
\text { 6. The same time using modified VIKOR and DEMATEL technique, } \\
\text { the decision mode is more complicated. }\end{array}$ \\
\hline $\begin{array}{l}\text { Priority is based on } \\
\text { influential network } \\
\text { (based on DEMATEL) }\end{array}$ & $\begin{array}{l}\text { 1. Decisions are only based on influential network of dimensions } \\
\text { and criteria (based on DEMATEL) } \\
\text { 2. The decision mode is simpler } \\
\text { 3. Decisions have not considered performance gaps } \\
\text { 4. Decisions are less integrity improvement }\end{array}$ \\
\hline
\end{tabular}


is a considerable discrepancy between each other. In view of this, this study tries to consider all the interview samples collected as a group to make an overall performance analysis for China's cloud auditing providers, and preliminarily discuss the reference basis for the selection of cloud auditing providers in China's small and medium-sized CPA firms. The future study can consider selecting several major cloud auditing providers to perform the performance comparison analysis so as to provide better practical results. In addition, other methods can be considered, such as longitudinal studies, to identify other possible criteria. The performance evaluation approach in this study using the modified VIKOR method adopts an additive model only, thus, a non-additive model, such as the fuzzy integrals method, should be applied to evaluate the relative weights of each criterion, which could more suitably solve practical problems in the real world.

\section{Acknowledgements}

The authors are extremely grateful for the reviewers and journal editorial team's valuable comments on improving the quality of this research. This research was partially supported by grant MOST 107-2410-H-034-016 of the Ministry of Science and Technology, Taiwan.

\section{References}

Afshari, A., Mojahed, M., \& Yusuff, R. M. (2010). Simple additive weighting approach to personnel selection problem. International Journal of Innovation, Management and Technology, 1(5), 511-515.

AICPA, \& CICA. (2009). Generally accepted privacy principles: CPA and CA practitioner version. American Institute of Certified Public Accountants, Canadian Institute of Chartered Accountants.

AICPA. (2013a). Service organization controls - managing risks by obtaining a service auditor's report. Retrieved from https://www.rubinbrown.com/10957-378_soc_whitepaper.pdf

AICPA. (2013b). Information integrity, 1-24. Retrieved from https://www.aicpa.org/content/dam/aicpa/ interestareas/frc/assuranceadvisoryservices/downloadabledocuments/asec-information-integritywhite-paper.pdf

Axelsen, M., Green, P., \& Ridley, G. (2017). Explaining the information systems auditor role in the public sector financial audit. International Journal of Accounting Information Systems, 24, 15-31. https://doi.org/10.1016/j.accinf.2016.12.003

Bergh, L. I. V., Hinna, S., Leka, S., \& Zwetsloot, G. I. (2016). Developing and testing an internal audit tool of the psychosocial work environment in the oil and gas industry. Safety Science, 88, 232-241. https://doi.org/10.1016/j.ssci.2015.06.003

Buyya, R., Yeo, C. S., Venugopal, S., Broberg, J., \& Brandic, I. (2009). Cloud computing and emerging IT platforms: Vision, hype, and reality for delivering computing as the $5^{\text {th }}$ utility. Future Generation Computer Systems, 25(6), 599-616. https://doi.org/10.1016/j.future.2008.12.001

Cavalcante, E., Batista, T., Lopes, F., Delicato, F. C., Pires, P. F., Rodriguez, N., de Moura, A. L., \& Mendes, R. (2012, November). Optimizing services selection in a cloud multiplatform scenario. In 2012 IEEE Latin America Conference on Cloud Computing and Communications (LatinCloud) (pp. 31-36). Porto Alegre. https://doi.org/10.1109/LatinCloud.2012.6508154

Chahal, R. K., \& Singh, S. (2016). AHP-based ranking of cloud-service providers. In Information systems design and intelligent applications (pp. 491-499). New Delhi: Springer.

https://doi.org/10.1007/978-81-322-2755-7_51 
Chen, C., Yan, S., Zhao, G., Lee, B. S., \& Singhal, S. (2012). A systematic framework enabling automatic conflict detection and explanation in cloud service selection for enterprises. In 2012 IEEE Fifth International Conference on Cloud Computing (pp. 883-890). https://doi.org/10.1109/CLOUD.2012.95

Chen, F. H. (2015). Application of a hybrid dynamic MCDM to explore the key factors for the internal control of procurement circulation. International Journal of Production Research, 53(10), 2951-2969. https://doi.org/10.1080/00207543.2014.961210

Chen, F. H., Tzeng, G. H., \& Chang, C. C. (2015). Evaluating the enhancement of corporate social responsibility websites quality based on a new hybrid MADM model. International Journal of Information Technology \& Decision Making, 14(3), 697-724. https://doi.org/10.1142/S0219622015500121

Chen, F. H., \& Tzeng, G. H. (2015). Probing organization performance using a new hybrid dynamic MCDM method based on the balanced scorecard approach. Journal of Testing and Evaluation, 43(4), 1-14. https://doi.org/10.1520/JTE20130181

Chen, H. K., Lin, C. Y., \& Chen, J. H. (2014, April). A multi-objective evolutionary approach for cloud service provider selection problems with dynamic demands. In European Conference on the Applications of Evolutionary Computation (pp. 841-852). Berlin, Heidelberg: Springer. https://doi.org/10.1007/978-3-662-45523-4_68

Chou, D. C. (2015). Cloud computing risk and audit issues. Computer Standards \& Interfaces, 42, 137142. https://doi.org/10.1016/j.csi.2015.06.005

Dastjerdi, A. V., Tabatabaei, S. G. H., \& Buyya, R. (2010). An effective architecture for automated appliance management system applying ontology based cloud discovery. In $10^{\text {th }}$ IEEE/ACM International Conference on Cluster, Cloud and Grid Computing (CCGrid), 2010. Melbourne, Australia: IEEE. https://doi.org/10.1109/CCGRID.2010.87

Deng, D., Wen, S., Chen, F. H., \& Lin, S. L. (2018). A hybrid multiple criteria decision making model of sustainability performance evaluation for Taiwanese certified public accountant firms. Journal of Cleaner Production, 180, 603-616. https://doi.org/10.1016/j.jclepro.2018.01.107

Dong, X., Yu, J., Zhu, Y., Chen, Y., Luo, Y., \& Li, M. (2015). SECO: Secure and scalable data collaboration services in cloud computing. Computers \& Security, 50, 91-105.

https://doi.org/10.1016/j.cose.2015.01.003

Dowling, C., \& Leech, S. A. (2014). A big 4 firm's use of information technology to control the audit process: How an audit support system is changing auditor behavior. Contemporary Accounting Research, 31(1), 230-252. https://doi.org/10.1111/1911-3846.12010

Du, H., \& Li, Z. (2011). Online-backup system for cloud computing storage. Energy Procedia, 13, 81948202.

Gabus, A., \& Fontela, E. (1972). World problems, an invitation to further thought within the framework of DEMATEL. Battelle Geneva Research Center, Geneva, Switzerland.

Ghosh, N., Ghosh, S. K., \& Das, S. K. (2015). SelCSP: A framework to facilitate selection of cloud service providers. IEEE Transactions on Cloud Computing, 3(1), 66-79. https://doi.org/10.1109/TCC.2014.2328578

Godse, M., \& Mulik, S. (2009, September 21-25). An approach for selecting software-as-a-service (SaaS) product. In IEEE International Conference on Cloud Computing (pp. 155-158). Bangalore, India. https://doi.org/10.1109/CLOUD.2009.74

Gray, D. (2008). Forensic accounting and auditing: Compared and contrasted to traditional accounting and auditing. American Journal of Business Education, 1(2), 115-126.

https://doi.org/10.19030/ajbe.v1i2.4630

Hsu, W. C. J., Tsai, M. H., \& Tzeng, G. H. (2018). Exploring the best strategy plan for improving the digital convergence by using a hybrid MADM model. Technological and Economic Development of Economy, 24(1), 164-198. https://doi.org/10.3846/20294913.2016.1205531 
Hu, K. H., Chen, F. H., Tzeng, G. H., \& Lee, J. D. (2015). Improving corporate governance effects on an enterprise crisis based on a new hybrid DEMATEL with the MADM model. Journal of Testing and Evaluation, 43(6), 1395-1412. https://doi.org/10.1520/JTE20140094

Hu, K.-H., Jianguo, W., \& Tzeng, G.-H. (2018). Improving China’s regional financial center modernization development using a new hybrid MADM model. Technological and Economic Development of Economy, 24(2), 429-466. https://doi.org/10.3846/20294913.2016.1213195

Janvrin, D., Caster, P., \& Elder, R. (2010). Enforcement release evidence on the audit confirmation process: Implications for standard setters. Research in Accounting Regulation, 22(1), 1-17. https://doi.org/10.1016/j.racreg.2010.02.002

Kanagasabai, R. (2012). OWL-S based semantic cloud service broker. In IEEE $19^{\text {th }}$ International Conference on Web Services (ICWS) (pp. 560-567). IEEE: Honolulu, HI.

Kleijnen, J. P. C. (2005). An overview of design and analysis of simulation experiments for sensitivity analysis. European Journal of Operational Research, 164(2), 287-300.

https://doi.org/10.1016/j.ejor.2004.02.005

Ko, Y. C., \& Fujita, H. (2016). Evidential weights of multiple preferences for competitiveness. Information Sciences, 354, 211-221. https://doi.org/10.1016/j.ins.2016.03.024

Krishna, B. H., Kiran, S., Murali, G., \& Reddy, R. P. K. (2016). Security issues in service model of cloud computing environment. Procedia Computer Science, 87, 246-251. https://doi.org/10.1016/j.procs.2016.05.156

Kwon, H. K., \& Seo, K. K. (2014). A fuzzy AHP based multi-criteria decision-making model to select a cloud service. International Journal of Smart Home, 8(3), 175-180.

https://doi.org/10.14257/ijsh.2014.8.3.16

Lee, K., Park, C., \& Yang, H. D. (2013). Development of service verification methodology based on cloud computing interoperability standard. International Journal of Smart Home, 7(5), 57-66. https://doi.org/10.14257/ijsh.2013.7.5.06

Lee, K., Park, C., \& Yang, H. D. (2015). Development of a cloud computing interoperability-based service certification. International Journal of Security and its Applications, 9(12), 11-20. https://doi.org/10.14257/ijsia.2015.9.12.02

Limam, N., \& Boutaba, R. (2010). Assessing software service quality and trustworthiness at selection time. IEEE Transactions on Software Engineering, 36(4), 559-574. https://doi.org/10.1109/TSE.2010.2

Liou, J. J. H., Chuang, Y. H., \& Tzeng, G. H. (2014). A fuzzy integral-based model for supplier evaluation and improvement. Information Sciences, 266(10), 199-217. https://doi.org/10.1016/j.ins.2013.09.025

Liu, J., Huang, X., \& Liu, J. K. (2015). Secure sharing of personal health records in cloud computing: ciphertext-policy attribute-based signcryption. Future Generation Computer Systems, 52, 67-76. https://doi.org/10.1016/j.future.2014.10.014

Liu, K. M., Lin, J. C., Hsieh, J. C., \& Tzeng, G. H. (2018). Improving the food waste composting facilities site selection for sustainable development using a hybrid modified MADM model. Waste Management, 75, 44-59. https://doi.org/10.1016/j.wasman.2018.02.017

Liu, Q., Wang, G., \& Wu, J. (2012). Secure and privacy preserving keyword searching for cloud storage services. Journal of Network and Computer Applications, 35(3), 927-933. https://doi.org/10.1016/j.jnca.2011.03.010

Lu, M. T., Hu, S. K., Huang L. H., \& Tzeng, G. H. (2015). Evaluating the implementation of businessto-business m-commerce by SMEs based on a new hybrid MADM model. Management Decision, 53(2), 290-317. https://doi.org/10.1108/MD-01-2014-0012

Mackay, M., Baker, T., \& Al-Yasiri, A. (2012). Security-oriented cloud computing platform for critical infrastructures. Computer Law \& Security Review, 28(6), 679-686.

https://doi.org/10.1016/j.clsr.2012.07.007 
Mansouri, N. (2016). Adaptive data replication strategy in cloud computing for performance improvement. Frontiers of Computer Science, 10(5), 925-935. https://doi.org/10.1007/s11704-016-5182-6

Martens, B., \& Teuteberg, F. (2012). Decision-making in cloud computing environments: A cost and risk based approach. Information Systems Frontiers, 14(4), 871-893. https://doi.org/10.1007/s10796-011-9317-X

Martens, B., Teuteberg, F., \& Gräuler, M. (2011). Design and implementation of a community platform for the evaluation and selection of cloud computing services: A market analysis. In ECIS 2011 Proceedings. 215. Retrieved from https://aisel.aisnet.org/ecis2011/215

Mazalov, V., Lukyanenko, A., \& Luukkainen, S. (2015). Equilibrium in cloud computing market. Performance Evaluation, 92, 40-50. https://doi.org/10.1016/j.peva.2015.07.002

Menzel, M., Schönherr, M., \& Tai, S. (2013). (MC2) 2: criteria, requirements and a software prototype for cloud infrastructure decisions. Software: Practice and Experience, 43(11), 1283-1297. https://doi.org/10.1002/spe.1110

Nicolaou, C. A., Nicolaou, A. I., \& Nicolaou, G. D. (2012). Auditing in the cloud: challenges and opportunities. The CPA Journal, 82(1), 66-70.

Nie, G., She, Q., \& Chen, D. (2012). Evaluation index system of cloud service and the purchase decisionmaking process based on AHP. Proceedings of the 2011 International Conference on Informatics, Cybernetics, and Computer Engineering (ICCE2011). Melbourne, Australia: Springer.

Opricovic, S. (1998). Multicriteria optimization of civil engineering systems. Faculty of Civil Engineering Belgrade, 2(1), 5-21.

Opricovic, S., \& Tzeng, G. H. (2007). Extended VIKOR method in comparison with outranking methods. European Journal of Operational Research, 178(2), 514-529.

https://doi.org/10.1016/j.ejor.2006.01.020

Prosch, M. (2008). Protecting personal information using Generally Accepted Privacy Principles (GAPP) and continuous control monitoring to enhance corporate governance. International Journal of Disclosure and Governance, 5(2), 153-166. https://doi.org/10.1057/jdg.2008.7

Ramachandran, M., \& Chang, V. (2016). Towards performance evaluation of cloud service providers for cloud data security. International Journal of Information Management, 36(4), 618-625. https://doi.org/10.1016/j.ijinfomgt.2016.03.005

Ren, W., Yu, L., Gao, R., \& Xiong, F. (2011). Lightweight and compromise resilient storage outsourcing with distributed secure accessibility in mobile cloud computing. Tsinghua Science \& Technology, 16(5), 520-528. https://doi.org/10.1016/S1007-0214(11)70070-0

Repschläger, J., Wind, S., Zarnekow, R., \& Turowski, K. (2011, September 22-23). Developing a cloud provider selection model. In Enterprise Modelling and Information Systems Architectures (EMISA 2011) (pp. 163-176). Hamburg, Germany.

Saaty, T. L. (1990). How to make a decision: the analytic hierarchy process. European Journal of Operational Research, 48(1), 9-26. https://doi.org/10.1016/0377-2217(90)90057-I

Saaty, T. L. (1996). Decision making with dependence and feedback: Analytic network process. Pittsburgh: RWS Publications

Saaty, T. L. (2004). Decision making - the analytic hierarchy and network processes (AHP/ANP). Journal of Systems Science and Systems Engineering, 13(1), 1-35. https://doi.org/10.1007/s11518-006-0151-5

Sanayei, A., Mousavi, S. F., Abdi, M. R., \& Mohaghar, A. (2008). An integrated group decision-making process for supplier selection and order allocation using multi-attribute utility theory and linear programming. Journal of the Franklin Institute, 345(7), 731-747.

https://doi.org/10.1016/j.jfranklin.2008.03.005 
Shen, K. Y., \& Tzeng, G. H. (2016). Combining DRSA decision-rules with FCA-based DANP evaluation for financial performance improvements. Technological and Economic Development of Economy, 22(5), 685-714. https://doi.org/10.3846/20294913.2015.1071295

Shin, D. H. (2013). User centric cloud service model in public sectors: Policy implications of cloud services. Government Information Quarterly, 30(2), 194-203. https://doi.org/10.1016/j.giq.2012.06.012

Shkurti, R., \& Muça, E. (2014). An analysis of cloud computing and its role in accounting industry in Albania. Journal of Information Systems \& Operations Management, 8(2), 1-12.

Simon, H. A. (1955). A behavioral model of rational choice. The Quarterly Journal of Economics, 66(1), 99-118. https://doi.org/10.2307/1884852

Simon, H. A. (1956). Rational choice and the structure of the environment. Psychological Review, 63(1), 129-138. https://doi.org/10.1037/h0042769

Sood, S. K. (2012). A combined approach to ensure data security in cloud computing. Journal of Network and Computer Applications, 35(6), 1831-1838. https://doi.org/10.1016/j.jnca.2012.07.007

System and Organization Controls 3 Report. (2017, December). Retrieved from https://d1.awsstatic.com/ whitepapers/compliance/AWS_SOC3.pdf

Tarmidi, M., Rasid, S. Z. A., Alrazi, B., \& Roni, R. A. (2014). Cloud computing awareness and adoption among accounting practitioners in Malaysia. Procedia-Social and Behavioral Sciences, 164, 569-574. https://doi.org/10.1016/j.sbspro.2014.11.147

Toy, A., \& Hay, D. C. (2015). Privacy auditing standards. Auditing: A Journal of Practice \& Theory, 34(3), 181-199. https://doi.org/10.2308/ajpt-50932

Van Akkeren, J., Buckby, S., \& MacKenzie, K. (2013). A metamorphosis of the traditional accountant: An insight into forensic accounting services in Australia. Pacific Accounting Review, 25(2), 188-216. https://doi.org/10.1108/PAR-06-2012-0023

Wang, C., Wood, L. C., Abdul-Rahman, H., \& Lee, Y. T. (2016). When traditional information technology project managers encounter the cloud: Opportunities and dilemmas in the transition to cloud services. International Journal of Project Management, 34(3), 371-388.

https://doi.org/10.1016/j.ijproman.2015.11.006

Wang, F. Y., Zhang, H., \& Liu, D. (2009). Adaptive dynamic programming: an introduction. Computational Intelligence Magazine, 4(2), 39-47. https://doi.org/10.1109/MCI.2009.932261

Yang, J., Lin, W., \& Dou, W. (2013). An adaptive service selection method for cross-cloud service composition. Concurrency and Computation: Practice and Experience, 25(18), 2435-2454. https://doi.org/10.1002/cpe.3080

Yavuz, A. A., \& Ning, P. (2009, December). Baf: An efficient publicly verifiable secure audit logging scheme for distributed systems. In Computer Security Applications Conference, 2009. ACSAC'09. Annual (pp. 219-228). IEEE.

Yigitbasioglu, O. M. (2015). External auditors' perceptions of cloud computing adoption in Australia. International Journal of Accounting Information Systems, 18, 46-62. https://doi.org/10.1016/j.accinf.2015.09.001

Yu, J., Xiao, X., \& Zhang, Y. (2016). From concept to implementation: The development of the emerging cloud computing industry in China. Telecommunications Policy, 40(2), 130-146. https://doi.org/10.1016/j.telpol.2015.09.009

Yu, P. L. (1973). A class of solutions for group decision problems. Management Science, 19(8), 936-946. https://doi.org/10.1287/mnsc.19.8.936

Zhang, H., Ye, L., Shi, J., Du, X., \& Guizani, M. (2014). Verifying cloud service-level agreement by a third-party auditor. Security and Communication Networks, 7(3), 492-502.

https://doi.org/10.1002/sec.740 
Zhao, L., Ren, Y., Li, M., \& Sakurai, K. (2012). Flexible service selection with user-specific QoS support in service-oriented architecture. Journal of Network and Computer Applications, 35(3), 962-973. https://doi.org/10.1016/j.jnca.2011.03.013

Zheng, Z., Wu, X., Zhang, Y., Lyu, M. R., \& Wang, J. (2013). QoS ranking prediction for cloud services. IEEE Transactions on Parallel and Distributed Systems, 24(6), 1213-1222. https://doi.org/10.1109/TPDS.2012.285

Zhu, W., \& Lee, C. (2016). A security protection framework for cloud computing. Journal of Information Processing Systems, 12(3), 538-547.

Zhu, Y., Hu, H., Ahn, G. J., \& Yau, S. S. (2012). Efficient audit service outsourcing for data integrity in clouds. Journal of Systems and Software, 85(5), 1083-1095. https://doi.org/10.1016/j.jss.2011.12.024

Zionts, S., \& Wallenius, J. (1983). An interactive multiple objective linear programming, method for a class of underlying nonlinear utility functions. Management Science, 29(5), 519-529.

https://doi.org/10.1287/mnsc.29.5.519

\section{APPENDIX}

\section{A new hybrid modified MADM model, DEMATEL, DANP, and modified VIKOR}

\section{Appendix A. DEMATEL method}

The Geneva Research Centre (Gabus \& Fontela, 1972) first created DEMATEL technique to explain factor-related facets of social problems using a network relationship structure to map and confirm the interrelations among sub-factors for each factor. According to the basic concepts, the processes of the hybrid MADM models are constructed to address the issues of dynamicity and complexity in the real world by Tzeng's research group ( $\mathrm{Lu}, \mathrm{Hu}$, Huang, \& Tzeng, 2015; Chen et al., 2015). The DEMATEL technique involves the following steps illustrated below.

Step 1: Form the initial average matrix $Z$ using scores. Assume the number of experts $G$ and the criteria $n$ are requested to rate by pairwise comparison any two criteria using an integer scale from 0 (absolutely no influence) to 4 (very high influence), indicating the degree of influence of each criterion/factor $i$ on each other criterion/factor $j$. The answers of each expert forms the non-negative $n \times n$ matrix $\boldsymbol{X}^{g}=\left[x_{i j}^{g}\right]_{n \times n}, 1 \leq g \leq G$, where $\boldsymbol{X}^{1}, \ldots, \boldsymbol{X}^{g}, \ldots, \boldsymbol{X}^{G}$ are the answer matrices by the $G$ number of experts, and the elements of $\boldsymbol{X}^{g}$ are denoted by $x_{i j}^{g}$. Thus, an $n \times n$ average matrix $Z$ of all experts can be given by Eq. (A.1)

$$
\boldsymbol{Z}=\left[\begin{array}{ccccc}
z_{11} & \cdots & z_{1 j} & \cdots & z_{1 n} \\
\vdots & & \vdots & & \vdots \\
z_{i 1} & \cdots & z_{i j} & \cdots & z_{i n} \\
\vdots & & \vdots & & \vdots \\
z_{n 1} & \cdots & z_{n j} & \cdots & z_{n n}
\end{array}\right] .
$$

The average scores $z_{i j}=\frac{1}{G} \sum_{g=1}^{G} x_{i j}^{g}$ of the $G$ number of experts form an average matrix, called the initial direct relation matrix $Z=\left[z_{i j}\right]_{n \times n}$, indicating the degree of mutual influence among criteria. 
Step 2: Normalize the direct-influence average matrix $D$. Normalizing the initial average matrix $\boldsymbol{Z}$ by using Eqs. (A.2) and (A.3), the matrix $\boldsymbol{D}$ can be acquired, and the principal diagonal values are zero.

$$
\begin{aligned}
& \boldsymbol{D}=\mu \cdot \boldsymbol{Z} \\
& \mu=\min \left\{\frac{1}{\max _{1 \leq i \leq n} \sum_{j=1}^{n} z_{i j}}, \frac{1}{\max _{1 \leq j \leq n} \sum_{i=1}^{n} z_{i j}}\right\} .
\end{aligned}
$$

Step 3: Calculate the total-influence relation matrix $\boldsymbol{T}$. The total influence relation matrix $\boldsymbol{T}=\left[t_{i j}\right]_{n \times n}, i, j=1,2, \ldots, n$ is a $n \times n$ matrix obtained by summing the direct effects and indirect effects, as shown in Eq. (A.4):

$$
\boldsymbol{T}=\boldsymbol{D}+\boldsymbol{D}^{2}+\ldots+\boldsymbol{D}^{q}=\boldsymbol{D}(\boldsymbol{I}-\boldsymbol{D}), \text { when } \lim _{q \rightarrow \infty} \boldsymbol{D}^{q}=[\mathbf{0}]_{n \times n},
$$

where $\boldsymbol{I}$ is the identity matrix.

The total influence matrix $\boldsymbol{T}$ from the sum of each column $(\boldsymbol{s})$ and row $(\boldsymbol{r})$ is shown in Eqs. (A.5) and (A.6).

$$
\begin{aligned}
& \boldsymbol{r}=\left(r_{i}\right)_{n \times 1}=\left[\sum_{j=1}^{n} t_{i j}\right]_{n \times 1}=\left(r_{1}, \ldots, r_{i}, \ldots, r_{n}\right)^{\prime} ; \\
& \boldsymbol{s}=\left(s_{j}\right)_{n \times 1}=\left[\sum_{i=1}^{n} t_{i j}\right]_{1 \times n}^{\prime}=\left(s_{1}, \ldots, s_{j}, \ldots, s_{n}\right)^{\prime},
\end{aligned}
$$

where $r_{i}^{D}$ and $r_{i}^{C}$ denotes the row sum $\left[\sum_{j=1}^{n} t_{i j}\right]_{n \times 1}$ of each dimension $i$ and criterion $i$ (direct and indirect) on all other dimensions and criteria (factors) respectively. Furthermore, $s_{j}^{D / C}$ denotes the column sum $\left[\sum_{i=1}^{n} t_{i j}\right]_{1 \times n}^{\prime}$ of the total influence (direct and indirect) of each dimension/criterion $j$ on all of the other dimensions/criteria (factors). Therefore, note that when $j=i,\left(r_{i}^{C}+s_{i}^{C}\right)$ shows the degree of the total influences between each factor (criterion) $i$ with others. The values of $\left(r_{i}^{C}-s_{i}^{C}\right)$ divide the criteria into causal groups (positive) and affected groups (negative). In general, when $\left(r_{i}^{C(D)}-s_{i}^{C(D)}\right)$ is positive, then the criterion $i$ or dimension $i$ is part of the causal cluster affecting other criteria (factors). By contrast, if $\left(r_{i}^{C(D)}-s_{i}^{C(D)}\right)$ is negative, then the criterion $i$ or dimension $i$ is part of the affected cluster influenced by other criteria (factors). The IIRM of the total influence relation matrix $\boldsymbol{T}$ can be derived by drafting the dataset of $\left(r_{i}^{C(D)}+s_{i}^{C(D)}, r_{i}^{C(D)}-s_{i}^{C(D)}\right)$.

\section{Appendix B. DANP (DEMATEL-based on ANP) processes}

This study not only analyzed the relationships among the factors using DEMATEL technique, but also calculated the relative influential weights of criteria, called the DANP (DEMATELbased ANP). ANP (Analytic Network Process) was proposed by Saaty (1996) to address the problem of mutual dependence and feedback among dimensions only (criteria are still assumed to be independent), so that it can be applied to decision-making for complex interrelationships among dimensions. The strength of ANP was merged with DEMATEL can be 
to solve all dimensions and criteria are interrelationship and the DANP influence weightings can thus be determined, which is more suitable for real-life problem-solving than traditional methods. DANP can be arranged as follows.

Step 1: Find the total influence relation matrix for criteria $T_{C}$ of DEMATEL. The total relation matrix $\boldsymbol{T}_{C}$ is composed of each perspective/dimension/cluster. There are different degrees of influence relation for each criterion $t_{i j}$ of the matrix $\boldsymbol{T}_{C}$, as shown by Eq. (B.1)

(where $\sum_{j=1}^{m} m_{j}=n, m<n$, and $\boldsymbol{T}_{C}^{i j}$ is a $m_{i} \times m_{j}$ matrix):

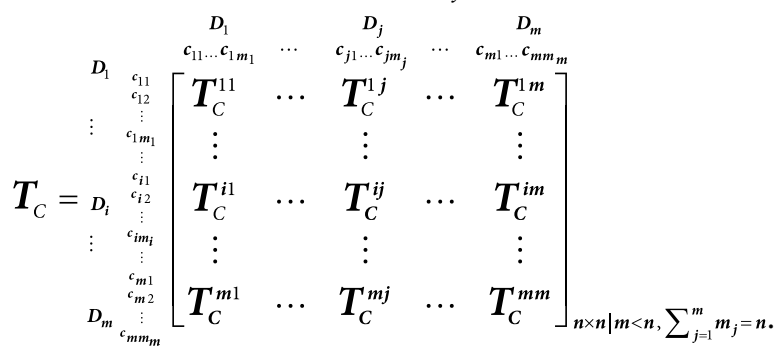

Here, $\boldsymbol{D}_{m}$ denotes the $m$ th cluster (dimension); $c_{m m}$ denotes the $m$ th criterion (indicator) of the $m$ th dimension (cluster); $T_{C}^{i j}$ denotes the sub-matrix, which is obtained through pairwise comparisons between the $i$ th and the $j$ th dimension.

Step 2: Normalized total influence relation matrix $T_{C}^{\beta}$. The normalized total influence matrix $T_{C}^{\beta}$ can be derived using Eq. (B.2)

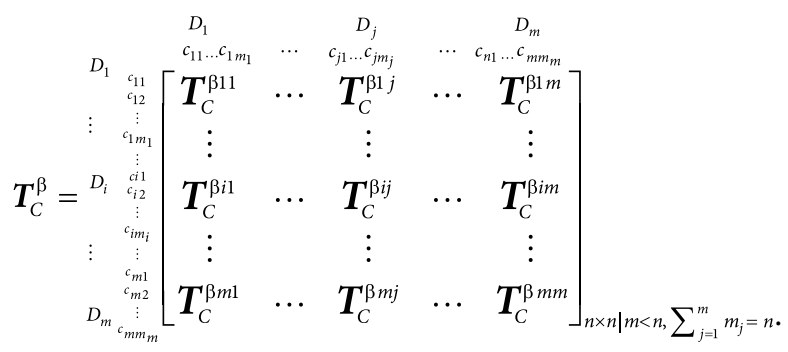

For example, an explanation for normalizing $T_{C}^{\beta 14}$ on dimension 1 based on dimension 4 ( $\beta 14)$ can be obtained via Eqs. (B.3) and (B.4); repeat to obtain $T_{C}^{\beta n n}$ :

$$
\begin{aligned}
& t_{i}^{14}=\sum_{j=1}^{m_{4}} t_{i j}^{14}, i=1,2, \cdots, m_{1} ;
\end{aligned}
$$

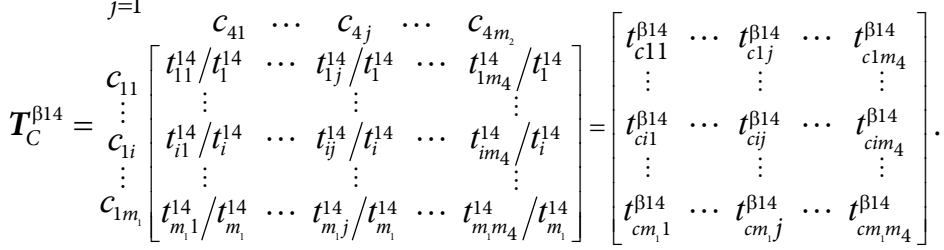

Here, $t_{c i j}^{\beta 14}=t_{i j}^{14} / t_{i}^{14}$ represents the factor (criterion) of normalized influence for the factor (criterion) $t_{i j}^{14}$. It also shows that the factor of $i$ influences another factor $j\left(j=1,2, \ldots, m_{4}\right)$ in which dimension 1 influences dimension 4; the total influence matrix is divided by the sum $t_{i}^{14}\left(i=1,2, \ldots, m_{1}\right)$ of each row whereby factor $i$ influences all other factors in dimension 4 . 
Step 3: Construct unweighted super-matrix $W$. Based on the basic ANP concepts to find the influential weights of DANP (DEMATEL-based ANP), and unweighted super-matrix $\boldsymbol{W}$ can be obtained by transposing the dimensions (cluster) of the normalized influence matrix $T_{C}^{\beta}$; that is, $W=\left(T_{C}^{\beta}\right)^{\prime}$ as shown by Eq. (B.5):

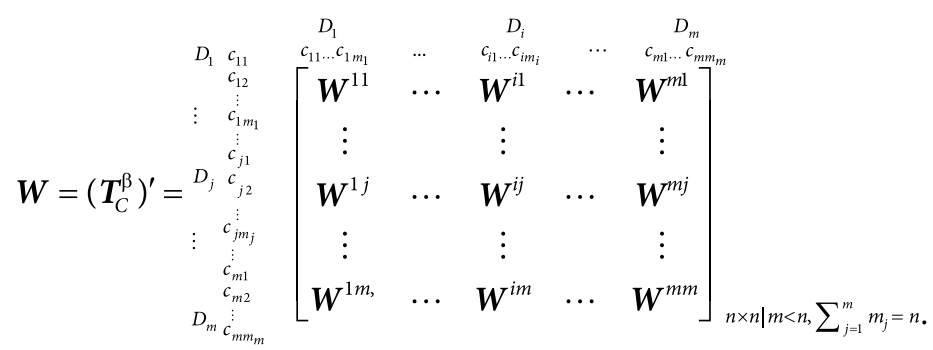

Step 4: Find the weighted super-matrix $W^{\beta}$. The total influence matrix of the dimensions matrix $\boldsymbol{T}_{D}$ is derived based on DEMATEL, as shown in Eq. (B.6):

$$
\boldsymbol{T}_{D}=\left[\begin{array}{ccccc}
t_{D}^{11} & \cdots & t_{D}^{1 j} & \cdots & t_{D}^{1 m} \\
\vdots & & \vdots & & \vdots \\
t_{D}^{i 1} & \cdots & t_{D}^{i j} & \cdots & t_{D}^{i m} \\
\vdots & & \vdots & & \vdots \\
t_{D}^{m 1} & \cdots & t_{D}^{m j} & \cdots & t_{D}^{m m}
\end{array}\right]_{m \times m}
$$

Normalization of the total influence matrix of the dimensions $\boldsymbol{T}_{D}^{\beta}$ can be derived by taking the total influence matrix $\boldsymbol{T}_{D}$ and dividing it by $d_{i}=\sum_{j=1} t_{D}^{i j}, i=1,2, \ldots, n$, as shown
in Eq. (B.7):

$$
\boldsymbol{T}_{D}^{\beta}=\left[\begin{array}{ccccc}
t_{D}^{11} / d_{1} & \cdots & t_{D}^{1 j} / d_{1} & \cdots & t_{D}^{1 m} / d_{1} \\
\vdots & & \vdots & & \vdots \\
t_{D}^{i 1} / d_{i} & \cdots & t_{D}^{i j} / d_{i} & \cdots & t_{D}^{i m} / d_{i} \\
\vdots & & \vdots & & \vdots \\
t_{D}^{m 1} / d_{m} & \cdots & t_{D}^{m j} / d_{m} & \cdots & t_{D}^{m m} / d_{m}
\end{array}\right]_{m \times m}=\left[\begin{array}{ccccc}
t_{11}^{\beta D} & \cdots & t_{1 j}^{\beta D} & \cdots & t_{1 m}^{\beta D} \\
\vdots & & \vdots & & \vdots \\
t_{i 1}^{\beta D} & \cdots & t_{i j}^{\beta D} & \cdots & t_{i m}^{\beta D} \\
\vdots & & \vdots & & \vdots \\
t_{m 1}^{\beta D} & \cdots & t_{m j}^{\beta D} & \cdots & t_{m m}^{\beta D}
\end{array}\right]_{m \times m}
$$

The weighted super-matrix $W^{\beta}$ (normalized super-matrix) can be easily derived by multiplying the normalized $T_{D}^{\beta}$ by unweighted super-matrix $W$ (Eq. (A.11)) using Eq. (B.8):

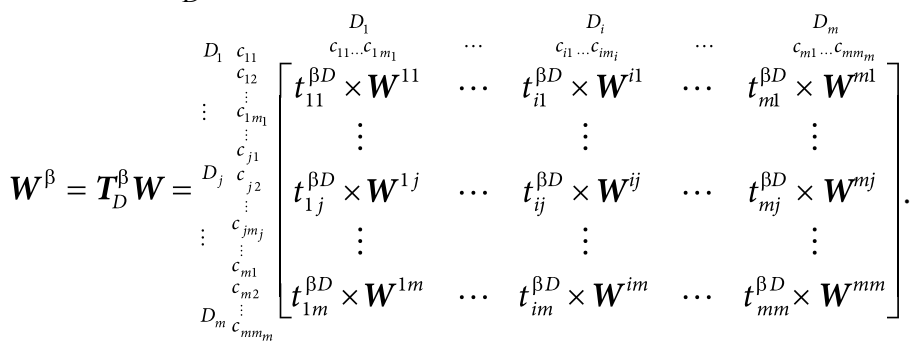

Step 5: Find the limits super-matrix. To obtain the DANP (DEMATEL-based ANP) influence weight (global influential weights), we raise the weighted super-matrix $W^{\beta}$ until it converges into a long-term stable super-matrix to obtain the weight of each assessment criterion; that is, $\lim _{q \rightarrow \infty}\left(\boldsymbol{W}^{\beta}\right)^{q}$, where $q$ represents any number for power. 


\section{Appendix C. Modified VIKOR}

Opricovic and Tzeng (2007) proposed the VIKOR technique, which could be used to resolve the problem of criterion conflict within the MADM model. The VIKOR technique measures the distance of all real performance values $\left\{f_{p j} \mid j=1,2, \ldots, n\right\}$ to ideal solutions $\left\{f_{j}^{*} \mid j=1,2, \ldots, n\right\}$, and the concept of approximating the aspiration level is used to correct the basic concepts of the traditional VIKOR method (Chen, 2015; Chen et al., 2015; Hu et al., 2015). The approximate distance to the positive ideal solution is the concept of the ratio-gap: $r_{p j}=\left(\left|f_{j}^{\text {positive-ideal }}-f_{p j}\right|\right) /\left(\left|f_{j}^{\text {positive-ideal }}-f_{j}^{\text {negative-ideal }}\right|\right)=\left(\left|f_{j}^{*}-f_{p j}\right|\right) /\left(\left|f_{j}^{*}-f_{j}^{-}\right|\right)=\left(\left|f_{j}^{\max }-f_{p j}\right|\right) /$ $\left(\left|f_{j}^{\max }-f_{j}^{\min }\right|\right)$ in traditional VIKOR, which was replaced by “aspiration-worst" level, the ratio-gap $r_{p j}=\left(\left|f_{j}^{\text {aspiration }}-f_{p j}\right|\right) /\left(\left|f_{j}^{\text {aspiration }}-f_{j}^{\text {worst }}\right|\right)$ in the modified VIKOR. From another point of view, the aspiration level originating from the modified VIKOR method is used as a substitute for an ideal level (the relatively higher solution) derived from an existing alternative traditional VIKOR method to help decision-makers more properly not only can use to implement the ranking and selection, but also can use to implement the performance improvement. Using this concept of "aspiration-worst" to replace "Min-Max", the basic concept of classical selection as the optimum level for decision-making was suggested by Nobel Prize winner Simon $(1955,1956)$. Through the determination of the aspiration level at each stage, the decision-making process is considered to be a continuous improvement and enhancement process. The procedures can be summarized in the following steps.

Step 1: Examine the aspiration level and the worst value. The aspiration levels (optimal values) $f_{j}^{\text {aspiration }}$ and the worst values $f_{j}^{\text {worst }}$ ("aspiration-worst") of assessment criteria $j$ can be obtained from the traditional "max-min" approach to the modified approach.

(1) Positive-ideal point and negative-ideal point from the traditional approach:

Positive-ideal point: $\boldsymbol{f}^{*}=\left(f_{1}^{*}, \ldots, f_{j}^{*}, \ldots, f_{n}^{*}\right)$,

where $f_{j}^{*}=\max _{p}\left\{f_{p j} \mid k=1,2, \ldots, P\right\}$;

Negative-ideal point: $\boldsymbol{f}^{-}=\left(f_{1}^{-}, \ldots, f_{j}^{-}, \ldots, f_{n}^{-}\right)$,

where $f_{j}^{-}=\min _{p}\left\{f_{p j} \mid k=1,2, \ldots, P\right\}$.

This approach must be at least two or more alternatives (i.e., $k \geq 2$ ) for ranking and selection.

(2) Aspiration level and worst value from the modified approach:

Aspiration level: $\boldsymbol{f}^{\text {aspiration }}=\left(f_{1}^{\text {aspiration }}, \ldots, f_{j}^{\text {aspiration }}, \ldots, f_{n}^{\text {aspiration }}\right)$, where $f_{j}^{\text {aspiration }}$ represents the aspiration level;

Worst value: $\boldsymbol{f}^{\text {worst }}=\left(f_{1}^{\text {worst }}, \ldots, f_{j}^{\text {worst }}, \ldots, f_{n}^{\text {worst }}\right)$,

where $f_{j}^{\text {worst }}$ represents the worst value.

This approach not only can be used for ranking and selection, but also can be used for performance improvement, even can be used only one (single) alternative for performance improvement.

The performance scores in this study can be obtained with a scale ranging from 0 to 10 points (very bad/dissatisfaction $\leftarrow 0,1,2, \ldots, 9,10 \rightarrow$ very good/satisfaction) in providing a semantic analysis of questionnaires using natural language. In the modified method, 
$f_{j}^{\text {aspiration }}=10$ therefore denotes the aspiration level (the highest score) while $f_{j}^{\text {worst }}=0 \mathrm{im}$ plies the worst value (the lowest score), thus avoiding choosing the best options/alternatives among the worst values. In other words, "picking the best apple in a rotten barrel" can be avoided.

Step 2: Calculate the mean regret group utility $S_{p}$ and the maximal gap $Q_{p}$. These gapvalues can be measured using Eqs. (C.1) and (C.2).

$$
\begin{aligned}
S_{p} & =\sum_{j=1}^{n} w_{j} r_{p j}=\sum_{j=1}^{n} w_{j}\left(\left|f_{j}^{\text {aspiration }}-f_{p j}\right|\right) /\left(\left|f_{j}^{\text {aspiration }}-f_{j}^{\text {worst }}\right|\right) ; \\
Q_{p} & =\max _{j}\left\{\left(\left|f_{j}^{\text {aspiration }}-f_{p j}\right|\right) /\left(\left|f_{j}^{\text {aspiration }}-f_{j}^{\text {worst }}\right|\right) \mid j=1,2, \ldots, n\right\} .
\end{aligned}
$$

Here, $S_{p}$ represents the ratios of the aspiration level distance and implies a minimum of the synthesized/integrated ratio-gaps for all criteria; $w_{j}$ indicates the influential weight of criteria $j$ from DANP, while $r_{p j}$ denotes the normalized gap ratio of alternative $p$ in the aspiration level. In addition, $Q_{p}$ represents the ratios of the worst value distance, implying the maximal gap in criterion $j$, which should therefore be the improvement priority.

Step 3: Find the comprehensive performance criteria $\boldsymbol{R}_{\boldsymbol{p}}$. The values can be calculated by Eq. (C.3):

$$
R_{p}=v\left(S_{p}-S^{*}\right) /\left(S^{-}-S^{*}\right)+(1-v)\left(Q_{p}-Q^{*}\right) /\left(Q^{-}-Q^{*}\right)
$$

Here, $S^{*}=\min _{p} S_{p}, \quad S^{-}=\max _{p} S_{p}, \quad Q^{*}=\min _{p} Q_{p}, \quad Q^{-}=\max _{p} Q_{p}, \quad$ and $\quad 0 \leq v \leq 1$, where $v$ indicates the gap weight of the maximal group utility, and $1-v$ indicates the individual regret weight (maximal gap and improvement priority). When $S^{*}=S^{\text {aspiration }}=0$, $Q^{*}=Q^{\text {aspiration }}=0$ (ie., $S^{*}=Q^{*}=0$ represents all criteria achieving the aspiration levels), $S^{-}=S^{\text {worst }}=1$, and $Q^{-}=Q^{\text {worst }}=1$, Eq. (C.3) can be rewritten as $R_{p}=v S_{p}+(1-v) Q_{p}$; that is, the traditional VIKOR is replaced by the modified VIKOR. Generally, $v=0.5$ can be set, while this can be adjusted based on the viewpoints of experts.

In sum and in short, using the modified VIKOR graded and each improved criterion performance gap while using IIRM's sorted and selected attributes thereby avoids "stop-gap measures". The hybrid MADM model proposed in this research can be applied to analyze any daily problem and can improve the performance gap after careful consideration of all the perspectives and criteria. 